\title{
Preparation of bioglasses developed from bypass cement dust for bone regeneration and comparing their radiation damage prediction with natural bone
}

\author{
Aiyeshah Alhodaib ${ }^{1 *}$, Suzy Abd El All ${ }^{1,2}$, Omnia Ibrahim $^{3}$, Fatthy Ezzeldin ${ }^{3}$ \\ ${ }^{1}$ Department of Physics, College of Science, Qassim University, Buraydah 51452, Saudi Arabia \\ ${ }^{2}$ Radiation Physics Department, National Center for Radiation Research \& Technology, Atomic Energy \\ Authority, Cairo 11787, Egypt \\ ${ }^{3}$ Radiation Chemistry Department, National Center for Radiation Research \& Technology, Atomic \\ Energy \\ Authority, Cairo 11787, Egypt \\ *Correspondence: ahdieb@qu.edu.sa
}

\begin{abstract}
Selected glasses with $10 \mathrm{Na}_{2} \mathrm{O}+(90-\mathrm{x}) \mathrm{P}_{2} \mathrm{O}_{5}+\mathrm{x}$ BCD where bypass cement dust $(\mathrm{BCD}) \mathrm{x}$ value $=10,20,30$ in $\mathrm{mol} \%$ were synthesized by recognizable melting annealing technique. Cooperative characterization of the prepared glasses were carried out through FTIR and SEM analysis before and after immersed in simulated body fluid (SBF) solution for 13 and 23 days at $37{ }^{\circ} \mathrm{C}$. After immersion in $\mathrm{SBF}$, apatite layer is produced on the glass surface after 13 day and increase after 23 day, showing good bioactivity after immersion in the SBF especially for bioglass sample with $30 \%$ BCD. A porous hydroxy apatite layer produced on the surface of SBF-glass composite and this layer became denser after more soaking time, periods were extended from 13 to 23 days. Atomic absorption spectroscopy explained the early period of soaking that cause release of both $\mathrm{Si}$ and $\mathrm{Ca}$ ions through the glass beside decreasing of phosphrous ions. Bioglass (BCD-30) is studied as shielding for gamma, protons and alphas by using Phy-X software, SRIM Monte Carlo simulation code and its subroutine TRIM. The gamma shielding parameters, mass stopping power (MSP), range for both proton ( $\mathrm{H}$ - ions) and alpha (He- ions) in bioglassBCD-30 and human bone tissue have estimated. Also, comparison between them is calculated in predicting the radiation damage and atomic displacements per atom (dpa).
\end{abstract}

Keywords: bypass cement dust; bioglass; FTIR; atomic displacement; radiation damage

\section{Introduction}

Bone repair acceleration and improvement has still slightly unmet needs for bone regeneration therapy. In this regards; bioglass is a promising field to achieve this goal. Positive impacts of bioglass on bone regeneration help in using BGs routinely in the clinical setting for osteoporosis patient. One of the most important implantable materials is bioglass (BG) that play a vital role in the treatment of variety of bone diseases and illnesses [1,2]. Fifty years after the invention of Hench's 45S5 formulation, many commercially manufactured BGs are used as an effective alternative to hard tissue engineering. Several types of phosphate, borate and silicate bioglass (BG) have been studied and characterized to be used for repairing bone defects. Important benefits were cited in relation to their use in bone regeneration. This includes the ability to attach to living tissue and improve osteoblast growth $[3,4]$. 
The release of some metal ions (eg, silicate and calcium ions) into surrounding biological media is the primary cause of these ability [5,6]. As a result, the researchers mix various ions within the glass structure to achieve beneficial biological effects. BGs' ionic dissolution products do indeed promote the production and secretion of biochemical markers involved in bone repair and regeneration $[7,8]$.

Larry Hench has defined the bioactivity of any material as as the property of the material to form very tight bond among the bone tissues and biomaterial [9]. This strong bone-biomaterial bond is due to bone-like hydroxyl-apatite layer (HAL) that formed on the surface of the biomaterial.

HAL mechanism formation on the surface of the glass involve both (a) hydroxylapatite nucleation on the glass surface by the aid of $\mathrm{Si}$ ions which make pores and tunnels for the beginning of Ca-P layer formation for the second step, (b) hydroxylapatite growth by longer time of immersion for the samples in the SBF where densed hydroxy-apatite layer is formed depending on the dissolution of more $\mathrm{Ca}$ and $\mathrm{Si}$ iond from biomaterial glass with the decrease of $\mathrm{P}$ ions from SBF solution. The main requirement to make artificial bone that is able to bond with natural bone. Hydroxylapatite layer is seems to be similar to natural bone composition, so surrounded natural bone can be able to contact directly with this hydroxyl-apatite layer by chemical reaction between surrounding $\mathrm{SBF}$ and the artificial bone $[10,11]$.

The cement industry produces about 4.1 billion tons of cement annually over worldwide [12]. Waste generated in the cement industry has low market value as dust scattered in the air. This dust can be found as two types, cement kiln dist (CKD) which is partially calcinated and bypass cement dust (BCD) which is completely calcinated. The high alkaline nature of BCD make it reacts with moisture and causing pulmonary diseases. According to the WHO Global Ambient Air Quality Database (updated 2018) [13], over seven million of people have died each year from some diseases as heart diseases strokes, pneumonia, lung cancer and chronic obstructive pulmonary diseases by exposure to tiny particles in polluted air $[12,13]$. Therefore, many studies have been focused on the addition of BCD into glass composition for several purposes

Ionizing radiation is increasingly being used in society for a variety of purposes, including medical, scientific, and industrial applications [14, 15]. Also, treatment with charged particles as protons and alpha has lately rekindled interest in contemporary radiation. The loss of energy and the distribution of particles or ions in humane tissues and shielding materials are critical in most studies. Detecting the generated effects from different irradiation sources are calculated, to simulate the patient exposure to radiotherapy, X-ray examination or any radiation accident [16] by determining stopping power and ion ranges using simulation computer models [17].

Where, energetic ions undergo several interactions with the matter before losing their kinetic energy by inelastic energy transfer to electrons (which causes excitation, and ionizing of target atoms and ions themselves), while the elastic energy transfer to atomic nuclei (recoils), and the high-energy effects (e.g. nuclear reactions and bremsstrahlung) [18]. The rate of energy loss per unit route length ( $\mathrm{dE} / \mathrm{dx})$ is measured by stopping power, also known as stopping force [19]. Briefly, ion energy losses fall into two categories: (1) energy transfer to the target electron that induces 
ionization (electron stopping power, $\mathrm{dE} / \mathrm{dx}$ ) and (2) energy transfer to the target nucleus (nuclear stopping power, $\mathrm{dE} / \mathrm{dx}$ ), which leads to atomic displacement or phonon energy dissipation for energy transfer above or below the threshold displacement energy (Ed) [20].

\subsection{Theoretical aspect}

The particle's kinetic energy is also reduced throughout the process, either through energy transfers to electrons (collision loss) or to bremsstrahlung photons (radiative loss). Collision stopping power and radiative stopping power are the two components of the stopping power for charged particle interactions.

$\left(-\frac{d E}{d x}\right)_{\mathrm{tot}}=\left(-\frac{d E}{d x}\right)_{\mathrm{col} .}+\left(-\frac{d E}{d x}\right)_{\mathrm{rad}}$

The Coulomb interaction between a charged particle and the nuclei of the absorber create the radiative stopping power. When compared to collision losses with orbital electrons, this number is generally small, especially for highly charged particles like protons, alpha particles, and so on. As a result, Coulomb interactions of energetic charged particles with orbital electrons of absorber atoms are primarily responsible for energy transfer from energetic charged particles to an absorber they pass through. The Bethe formula, developed in quantum physics and relativity, theoretically gives the mass stopping power (in $\mathrm{MeV} \mathrm{cm} / \mathrm{g}$ ) of an absorber for a specific type of charged particle.

$\left(-\frac{d E}{\rho d x}\right)_{\text {col. }}=\frac{4 \pi e^{4} z^{2} Z N_{A}}{m_{e} c^{2} \beta^{2} A}\left\{\ln \left(\frac{2 m_{e} c^{2} \beta^{2}}{I\left(1-\beta^{2}\right.}\right)-\beta^{2}\right\}$

where $\mathrm{Z}$ and $\mathrm{z}$ are the atomic numbers of the absorber and the incoming charged particle, respectively; $A$ is the absorber's atomic mass; and $\mathrm{N}_{\mathrm{A}}$ is Avogadro's number; e denotes an electron's charge; $\mathrm{m}_{\mathrm{e}} \mathrm{c}^{2}$ denotes an electron's rest energy $(0.511 \mathrm{MeV})$; $\mathrm{c}$ is the relative velocity of the incoming charged particle; and I denotes the absorber's mean ionization potential [21].

The SRIM code through Monte Carlo simulations includes a "Compound dictionary" with pre-defined parameters for the most frequent target materials, which are grouped into many categories, one of which is the "Biological materials - human" that will be used in this work. The SRIM code is commonly used to calculate electronic and nuclear stopping powers and to simulate the inelastic and elastic energy transfers from an energetic incident ion to target atoms as it passes through a sample until stopped for a quantitative comparison of the damage due to atomic displacement induced by different combinations of ionic targets. The resulting displacement generating profile is used to calculate the local damage in atomic displacement per atom and to evaluate the impact of energetically charged particles on the composition, structure, function and topography of the target surface [22].

The motivation of this work is to try to get new bioglass type through the reuse of bypass cement dust as an industrial waste causing pulmonary diseases to form valuable bioglass for bone regeneration due to it's high content of calcium and silicate which provide the prepared glassy system with the essential component for constructing the hydroxy-apatite layer (HAL). FTIR and SEM can be measured to confirm the formation of HAL. The study aims to simulate changes in bioglass-BCD implanted in patient when exposed to radiotherapy or any radiation accident and compare the estimated mass stopping power (MSP), projected range (PR) of protons (H- ions) and alpha (He-ions), the total displacement atoms and predicting damage 
between the natural bone tissue and the synthesis bioglass-BCD using SRIM Monte Carlo simulation code and its subroutine TRIM

\section{Experimental Methods}

\subsection{Glass Preparation}

Three glass samples have been prepared from different concentrations of bypass cement dust as an industrial waste with a composition $10 \mathrm{Na}_{2} \mathrm{O}-(90-\mathrm{x}) \mathrm{P}_{2} \mathrm{O}_{5}$ where $\mathrm{x}=10,20,30 \%$ of bypass cement dust. The mixture is shacked well, then molten at $1150{ }^{\circ} \mathrm{C}$ in muffle furnace for 2 hours. The molten samples were poured onto hot stainless steal then transferred into another hot furnace at $300{ }^{\circ} \mathrm{C}$ lefted to reach room temperature slowly. The glass samples are coded as BCD-10, BCD-20, BCD-30 as tabulated by Table 1

Table 1. Chemical composition of the prepared glasses

\begin{tabular}{|c|c|c|c|}
\hline \multirow{2}{*}{ Samples } & \multicolumn{3}{|c|}{ Chemical composition (mol \%) } \\
\cline { 2 - 4 } & BCD & $\mathbf{N a}_{2} \mathbf{O}$ & $\mathbf{P}_{\mathbf{2}} \mathbf{O}_{\mathbf{5}}$ \\
\hline BCD-10 & 10 & 10 & 80 \\
\hline BCD-20 & 20 & 10 & 70 \\
\hline BCD-30 & 30 & 10 & 60 \\
\hline
\end{tabular}

\subsection{Simultaneous Blood Fluid (SBF) Preparation}

Aqueous solutions $(50 \mathrm{~mL})$ of simultaneous blood fluid (SBF) were used to obtain immerse the samples and form hydroxyl apatite layer. SBF consists of inorganic concentration close to those in blood plasma. It is prepared from a mixture of sodium chloride $(\mathrm{NaCl})$, potassium chloride $(\mathrm{KCl})$, sodium bicarbonate $\left(\mathrm{NaHCO}_{3}\right)$, sodium sulphate $\left(\mathrm{NaSO}_{4}\right)$, calcium chloride $\left(\mathrm{CaCl}_{2}\right)$, magnesium chloride hexahydrate $\left(\mathrm{MgCl}_{2} \cdot 6 \mathrm{H}_{2} \mathrm{O}\right)$ and dibasic potassium hydrogen phosphate $\left(\mathrm{K}_{2} \mathrm{HPO}_{4} .3 \mathrm{H}_{2} \mathrm{O}\right)$ in deionized water with determined concentrations according to Table 2 which is equivalent to their total concentrations in human blood plasma. Then solution was buffered at hP 7.3 with tri hydroxymethyl amminomethane $\left[\left(\mathrm{CH}_{2} \mathrm{OH}\right)_{3} \mathrm{CNH}_{2}\right]$ and hydrochloric acid $(\mathrm{HCl})$ as mentioned by Hench 1991 [23].

Table 2. Ion concentration of SBF solution

\begin{tabular}{|c|c|c|c|c|c|c|c|}
\hline $\mathbf{M g}^{2+}$ & $\mathbf{C a}^{2+}$ & $\mathbf{H C O}_{3}{ }^{-}$ & $\mathbf{H P O}_{4}{ }^{2-}$ & $\mathbf{S O}_{4}{ }^{2-}$ & $\mathbf{K}^{+}$ & $\mathbf{C l}^{-}$ & $\mathbf{N a}^{+}$ \\
\hline 1.5 & 2.5 & 4.2 & 1.0 & 0.5 & 5.0 & 148.8 & 142.0 \\
\hline
\end{tabular}

\subsection{In Vitro Assays}

Samples were weighted and soaked in $10 \mathrm{ml}$ of SBF to cover the samples in polyethylene beakers at room temperature at periodic intervals (13 and 23 days), the samples were removed after this period of time and washed with distilled water to 
remove the excess $\mathrm{SBF}$, then allowed to air dry. The $\mathrm{pH}$ of the media was monitored by using the $\mathrm{pH}$ meter along the experiment where it was 7.4 in the beginning of the experiment and increase slightly to 8.36 at the end.

\subsection{Physicochemical characterization techniques of elaborated glass}

\subsubsection{FTIR investigation}

Structural groups inside the prepared glassy network and the formed hydroxyl apatite layer on the bioglass samples have been detected by the absorption spectra of range (400-4000 $\left.\mathrm{cm}^{-1}\right)$ through Fourier Transform infrared spectrometer model VERTEX 70 FTIR, Bruker's

\subsubsection{Atomic absorption spectrometry}

Atomic absorption spectrometry (AAnalyst 100, Perkin Elmer) was used to determine the bioactivity characters of the samples by determining the soluble concentrations of $\mathrm{Ca}, \mathrm{Si}$ and $\mathrm{P}$ ions (in $\mathrm{ppm}$ ) in the SBF after removing the samples..

\subsubsection{SEM and EDX investigations}

Scanning Electron Microscopy (SEM) connected with Energy Dispersive X-Ray Spectroscopy (EDX) (Zeiss EVO 18); SEM was used to follow the HAL formation on the glass surface. Samples were coated with gold to obtain good and clear pictures at RT before and when immersion in SBF. EDX analysis was carried out at specific conditions 5009, $12 \mathrm{~mm} \mathrm{WD}, 15 \mathrm{kV}$, mode to utilize the composition of $\mathrm{BCD}$ and to estimate the distribution of different chemical composition after glass preparation.

\section{Results and Discussion}

\subsection{FTIR Analysis}

Results of FTIR spectra of Figure 1 showed the main fundamental groups of the composition for samples BCD 10, BCD 20 and BCD 30 before immersion in SBF solution. Similar absorption peaks were observed after immersion in SBF for two different soaking times (13 and 23 days) except new peaks were observed related to hydroxyapatite layer. The main absorbed peaks were related to silica and phosphrous. Before immersion in SBF, peaks related to silica were located at $[24,25]$ :

- $\quad 471$ and $912 \mathrm{~cm}^{-1}$ for Si-O-Si bending vibration

- 530, 1035 and $1108 \mathrm{~cm}^{-1}$ for Si-O-Si stretching vibration due to metal oxide bond

- $\quad 870-990 \mathrm{~cm}^{-1}$ for Si-OH bending vibration

- $\quad 3440 \mathrm{~cm}^{-1}$ for bending vibration of Si-H and $\mathrm{Si}-\mathrm{OH}$.

Peaks related to phosphate group were located at [26, 27]:

- $471 \mathrm{~cm}^{-1}$ for O-P-O bending vibration and $\mathrm{PO}_{2}$ mode of $\left(\mathrm{PO}_{3}\right)_{\mathrm{n}}$ chain

- $530 \mathrm{~cm}^{-1}$ for $\mathrm{PbO}_{6}$ units vibration

- $760 \mathrm{~cm}^{-1} \mathrm{P}-\mathrm{O}-\mathrm{P}$ bridging of pyrophosphate $\left(\mathrm{P}_{2} \mathrm{O}_{7}\right)^{4-}$ for stretching symmetric vibration

- $\quad$ (850-912) $\mathrm{cm}^{-1} \mathrm{P}-\mathrm{O}-\mathrm{P}$ bridging of meta phosphate

- (1000-1150) $\mathrm{cm}^{-1}$ for $\mathrm{P}-\mathrm{O}$ terminal group of $\mathrm{PbO}_{3}$ units and $(\mathrm{PbO})_{\mathrm{n}}$ of tetrahedral units

- $1390 \mathrm{~cm}^{-1}$ for $\mathrm{O}-\mathrm{P}=\mathrm{O}$ asymmetrical stretching vibration of terminal group of $\left(\mathrm{PO}_{3}\right)^{2-}$ 


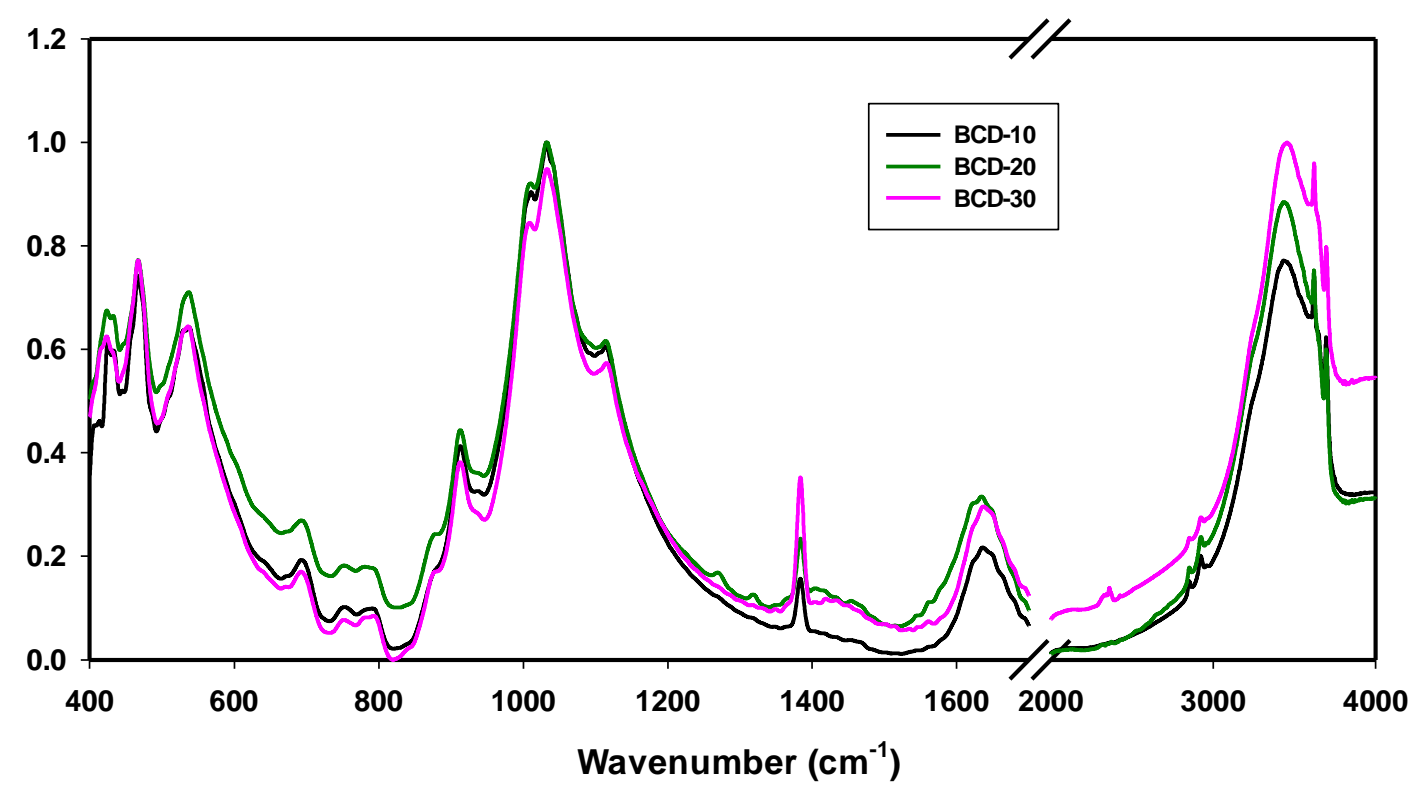

Figure (1) FTIR absorption spectrum of prepared glass samples

Figure 2 a,b and c; after immersion in SBF for two different times (13 and 23 days) the intensity of most of these peaks responsible for silica groups decreased due to formation of hydroxyapatite layer. Moreover; new formed peaks were detected which are characteristic of calcium phosphate of the apatite layer, the most observed results are detected in glass sample biglass-BCD-30 by the following peaks [28-30]:

- 569,601 and $633 \mathrm{~cm}^{-1}$ for calcium phosphate phase due to P-O bending

- 2927, 2858 and $1630 \mathrm{~cm}^{-1}$ for C-O, O-H and P-O were noticed for hydroxyl group in apatite structure

- 1416 and $1479 \mathrm{~cm}^{-1}$ for carbonate group in hydroxyl apatite

- $852 \mathrm{~cm}^{-1}$ for $\mathrm{CO}_{3}{ }^{2-}$ group

- $1045 \mathrm{~cm}^{-1}$ for reaction between phosphate solution and calcium.

- $1632 \mathrm{~cm}^{-1}$ for HAL which increase after immersion

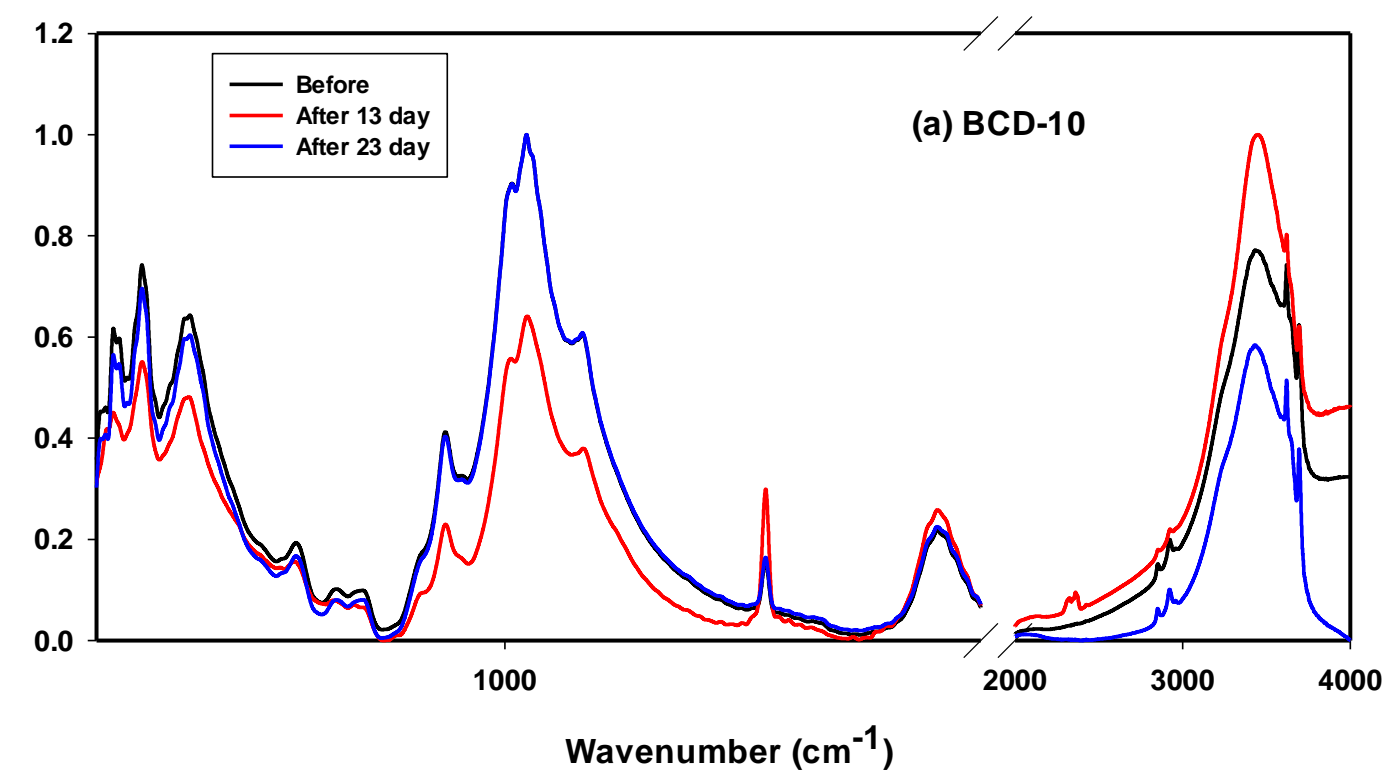



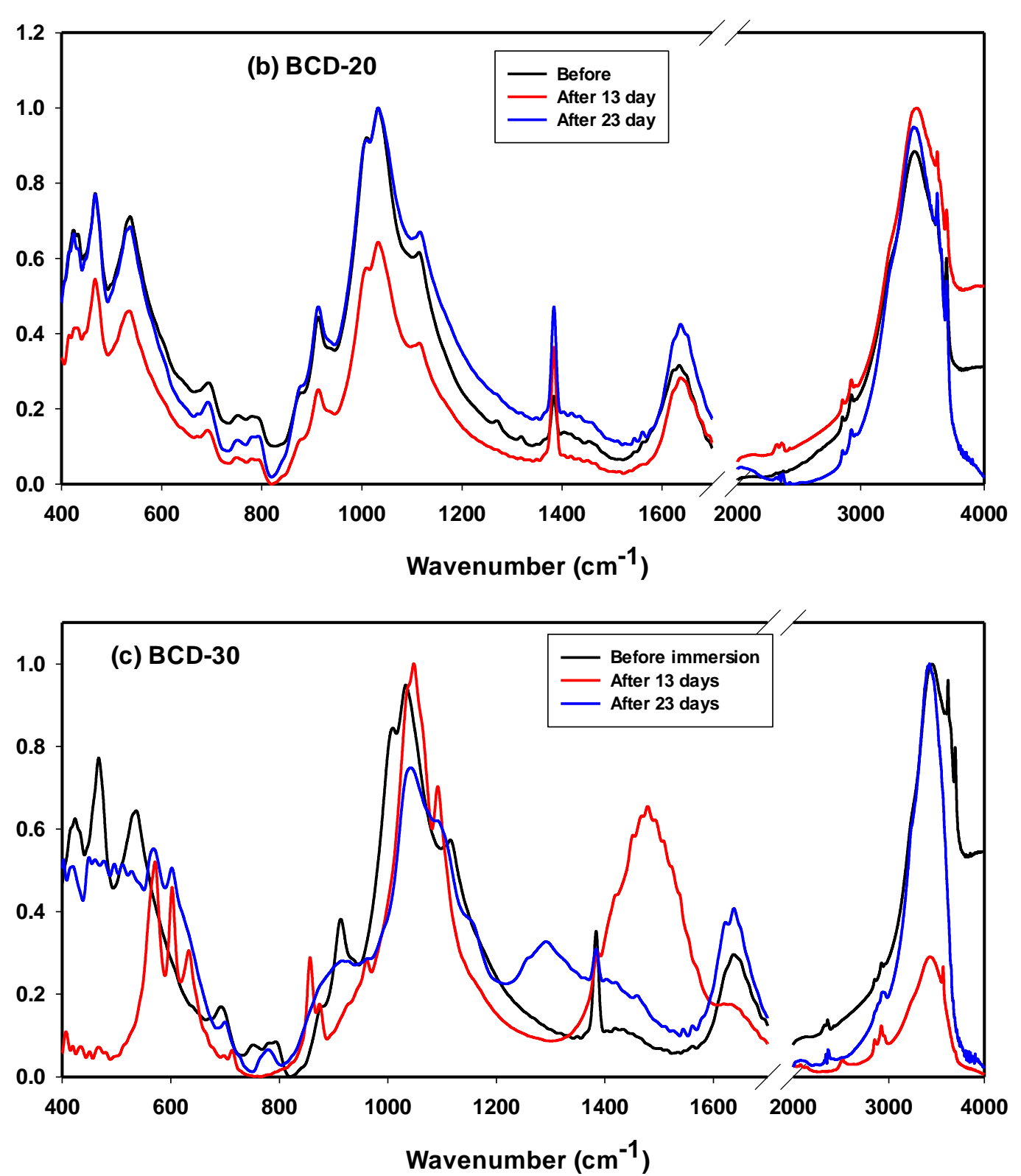

Figure 2. FTIR absorbance before and after immersion in SBF for different times for the prepared glass samples (a) BCD-10 (b) BCD-20 (c) BCD-30

The presence of $\mathrm{SiOH}$ groups on the glass surface, offering favorable conditions for hydroxyl apatite nucleation by formation of phosphate $\left(\mathrm{PO}_{4}\right)^{3-}$ and calcium $\mathrm{Ca}^{2+}$ ions on the surface of the glass $[29,30]$. As noticed, increasing the soaking time from 13 to 23 day; the intensity of P-O absorptions at $633 \mathrm{~cm}^{-1}$ beside the triple peaks responsible for calcium phosphate phase of P-O bending at 569, 601 and $633 \mathrm{~cm}^{-1}$ became stronger owing to the formation of denser of hydroxy apatite layer (HAL) on of the glass surface increased. Other peaks could not be distinguished well due to the overlapping with water.

The addition of further BCD up to $30 \%$ in glass improves the formation of hydroxyapatite layer on the glass surface by immersion in SBF by dissolution of $\mathrm{Ca}$ and $\mathrm{Si}$ ions in the solution that enhance bonding between induced glass surface and natural bone. 


\subsection{XRD Analysis}

Figure $3 a, b$ illustrate the amorphicity behavior of the prepared samples by appearing broad pattern and show how the samples keep their amorphous character even after immersed in SBF for 13 and 23 days.

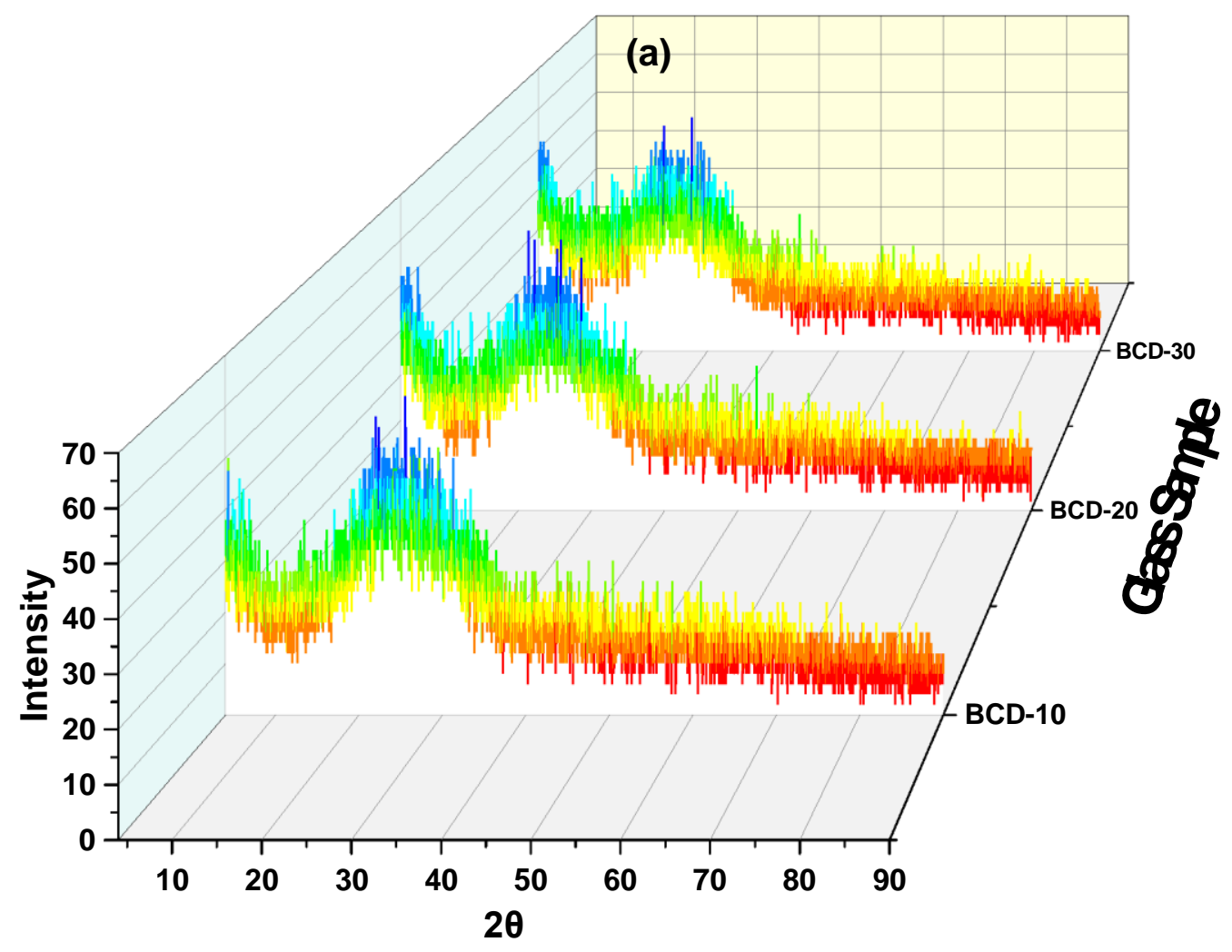




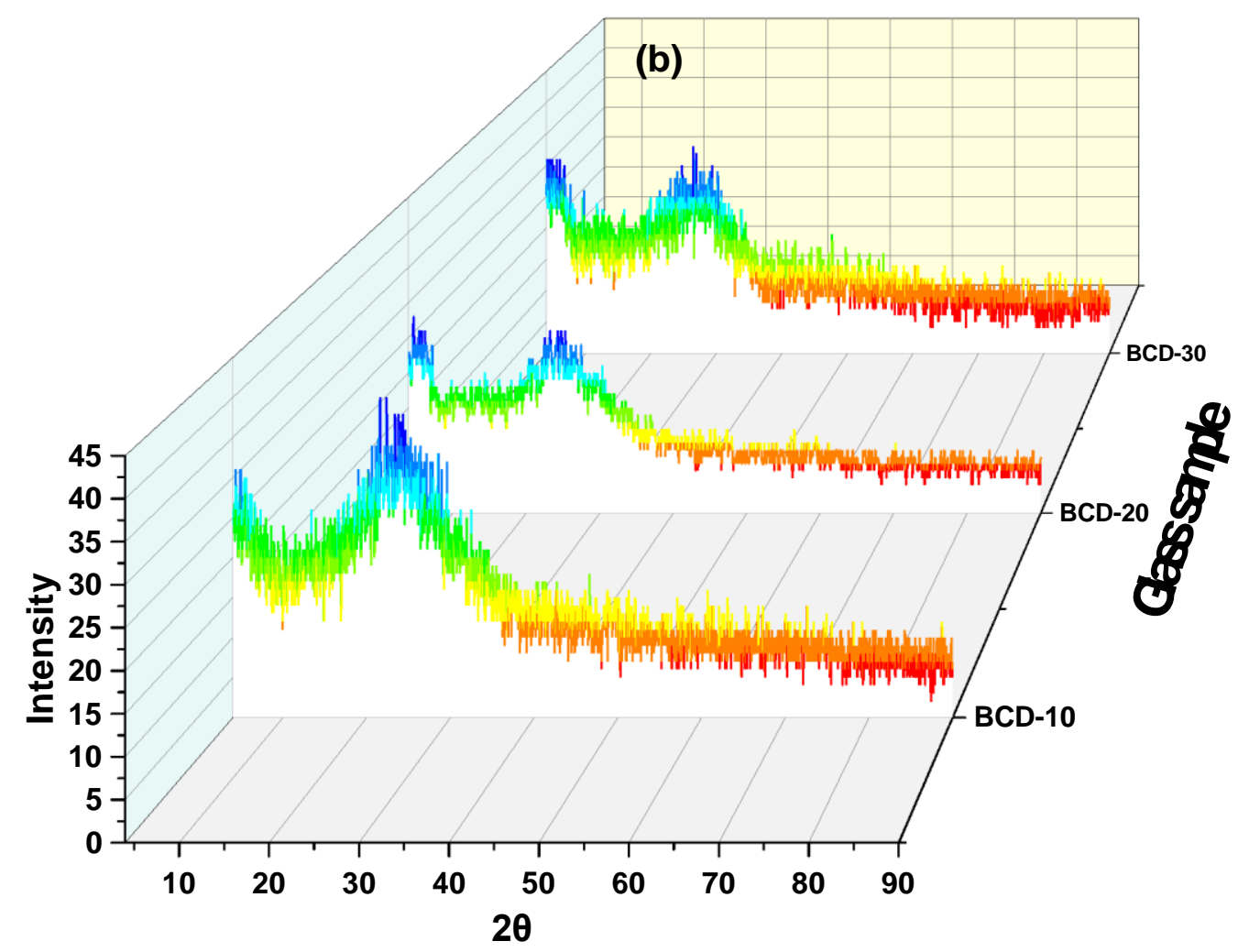

Figure 3. XRD of bioglass-BCD samples after immersion in SBF after (a) 13 (b) 23 day

It is known that hydroxy-apatite layer has crystalline behavior in XRD analysis and due to the covelenty bonding between hydroxyl apatite and glass surface the amorphous character is the dominant and can hide or overlap the peaks corresponding to HAL. But small changes can be compare after long period of immersion as in case BCD-10; the broad band extend from 11.2 to $47.2^{\circ}(2 \theta)$ after immersion by 13 day in SBF but after 23 day the band is shifted to extend from 9.6 to $36.4^{\circ}(2 \theta)$. In case of BCD-20; the broad band extends from 13.7 to $37^{\circ}$ after 13 day which shifted to be from 8.68 to $35.5^{\circ}$. While in case of BCD-30; the broad band begins from 10.48 to $43.46^{0}$ that shifted to start from 7.44 to $37.08^{0}(2 \theta)$. In addition; the three samples after immersion in SBF for 23 days show small splitting in the broad band which has not been found before in case of immersion for 13 day. All the last observations can prove the entrance of partially crystalline materials where its appearance is limited due to the amorphous glassy structure [31].

\subsection{Bioactivity Characterization by atomic absorption spectrometry}

Atomic Absorption Spectrometry is used to study the release process by follow the diffusion out of some ions $\left(\mathrm{Ca}^{2+}\right.$ and $\left.\mathrm{Si}^{4+}\right)$ from glass samples in the prepared $\mathrm{SBF}$ and the decease of $\mathrm{P}^{5+}$ ions from it; all are measured in ppm at Table 3. In early stages; the diffusion out of silica $\left(\mathrm{Si}^{4+}\right)$ and calcium $\left(\mathrm{Ca}^{2+}\right)$ ions from bioglass samples into the surrounding solution increase combined with decreasing in phosphrous $\left(\mathrm{P}^{5+}\right)$ ions due to the chemical exchange reaction [32]. For longer time of immersion; the amount of dissolved ions $\mathrm{Si}^{4+}$ and $\mathrm{Ca}^{2+}$ ions increase from 3.18 to $4.2 \mathrm{ppm}$ and fro 91.5 to $120.9 \mathrm{ppm}$; respectively while phosphrous ions decrease from 156.9 to 110.2 
ppm in case of BCD-30 sample. The other samples with different concentrations give similar behavior.

Table 3. Ion concentration in $\mathrm{mg} / \mathrm{L}$ after immersion in SBF for 13 and 23 days during bioactivity test

\begin{tabular}{|l|c|c|c|c|c|c|}
\hline Sample & \multicolumn{2}{|c|}{ Ca $^{2+}$} & \multicolumn{2}{c|}{ Si $^{4+}$} & \multicolumn{2}{c|}{ P $^{5+}$} \\
\cline { 2 - 7 } & 13 d & 23 d & 13 d & $\mathbf{2 3 ~ d}$ & 13 d & 23 d \\
\hline BCD-10 & 392.2 & 399.3 & 0.65 & 1.02 & 77.6 & 75.1 \\
\hline BCD-20 & 186.8 & 191.6 & 0.63 & 1.05 & 82.6 & 80.3 \\
\hline BCD-30 & 156.9 & 172.0 & 3.18 & 5.29 & 91.5 & 78.6 \\
\hline
\end{tabular}

Once the samples immersed in SBF; silica and calcium ions releasing into SBF is higher than the formation of hydroxyl-apatite layer which lead to degradation on the bioglass surface and forming slightly porous surface as a suitable layer for the beginning of the reaction [28]. This process is the first step for nucleation of hydroxyapatite layer that obtained after further immersion of time, calcium dissolved ions increase with decreasing in phosphrous amount followed by more hydroxyl-apatite precipitation on the glass surface. The process of forming hydroxyl-apatite layer can be explained owing to the role of silica ions to degrade the glass surface forming pores, then exchange between cations from the bioglass samples and $\mathrm{H}^{+}$inside SBF which results in changing $\mathrm{pH}$ of the fluid from 7.4 to higher value of 8.36 at the end of the experiment, this exchange mechanism can generate hydroxy-apatite layer on the bioglass surface $[32,33]$.

\subsection{SEM and EDX investigation data}

Figure 4a illustrate the main component of by pass cement dust obtained from local factory which contain about $48.95 \% \mathrm{Ca}^{2+}$ and $9.66 \% \mathrm{Si}^{4+}$ before added to glass component while after melting process for different glass composition; BCD-30 has been examined by EDX to show the accurate percent of sharing for several component after melting process by Figure $4 \mathrm{~b}$. Results from EDX figures were converted into metal oxide equivalents for easy reporting at Table 4 

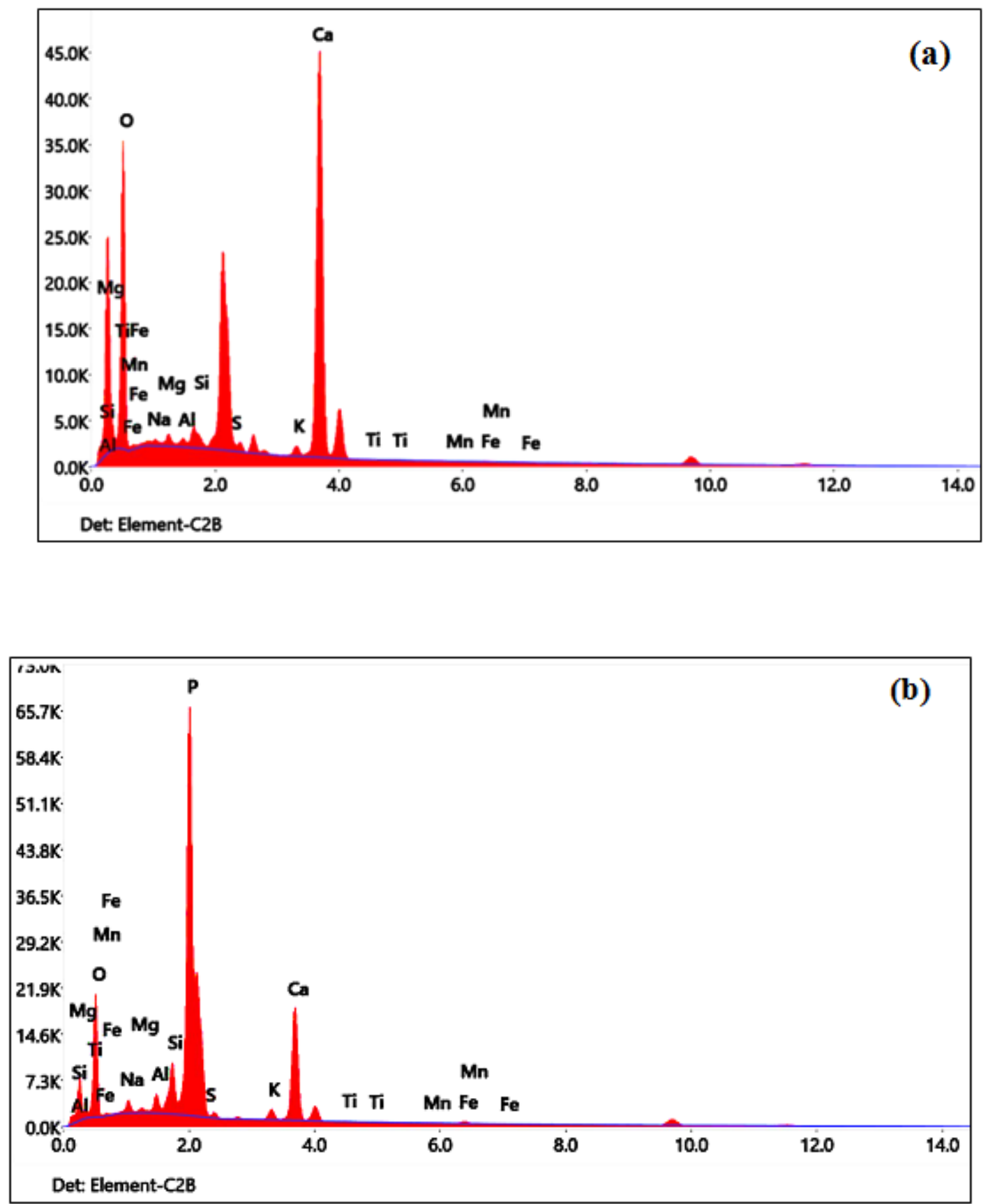

Figure 4. EDX spectra of (a) by pass cement dust (b) bioglass sample with $30 \% \mathrm{BCD}$ (BCD-30)

Table 4. Elemental analyses by EDX for bypass cement dust (BCD) and prepared bioglass doped by bypass cement dust (BCD)

\begin{tabular}{|l|l|l|l|l|l|l|l|l|l|l|l|}
\hline & \multicolumn{10}{|c|}{ Elements in (wt \%) } \\
\cline { 2 - 9 } Sample & Na & Mg & Al & Si & S & K & Ca & Ti & Mn & Fe & P \\
\hline
\end{tabular}




\begin{tabular}{|l|l|l|l|l|l|l|l|l|l|l|l|}
\hline BCD & 3.36 & 3.22 & 3.18 & 25.47 & 2.59 & 2.85 & 51.42 & 2.58 & 2.66 & 2.67 & -- \\
\hline BCD-30 & 6.44 & 1.19 & 1.01 & 18.64 & 1.53 & 1.36 & 36.53 & 1.2 & 1.22 & 1.24 & 29.64 \\
\hline
\end{tabular}

To assess the morphological changes linked to the structural differences, SEM micrographs of the synthesized samples were taken before and after immersion in SBF. Before immersion, all samples had the same smooth texture without any clusters or aggregations that prove the perfect distribution of mixed weighted component during melting process as given by Figure 5 ( $\mathrm{a}, \mathrm{b}$ and $\mathrm{c}$ ).

After immersion of 13 days in SBF solution; glass begin to give porous structure which is related to provide channels in the bioglass matrix for allowing the growth of the nature bone inside it and improving bioresorption [34]. While after 23 days of immersion, calcium phosphate film (Ca-P) and $\mathrm{SiO}_{2}$-rich architectures with cloudy HA particles begin to dispersed on the surface of bioglass samples and the layer show denser shape by adding higher concentration of BCD with appearing of cotton-like clusters on the surface at BCD-30 surface for highly dense hydroxyapatite formed layer which decrease the porosity level, as illustrated in Figure $6(a, b, c)$.

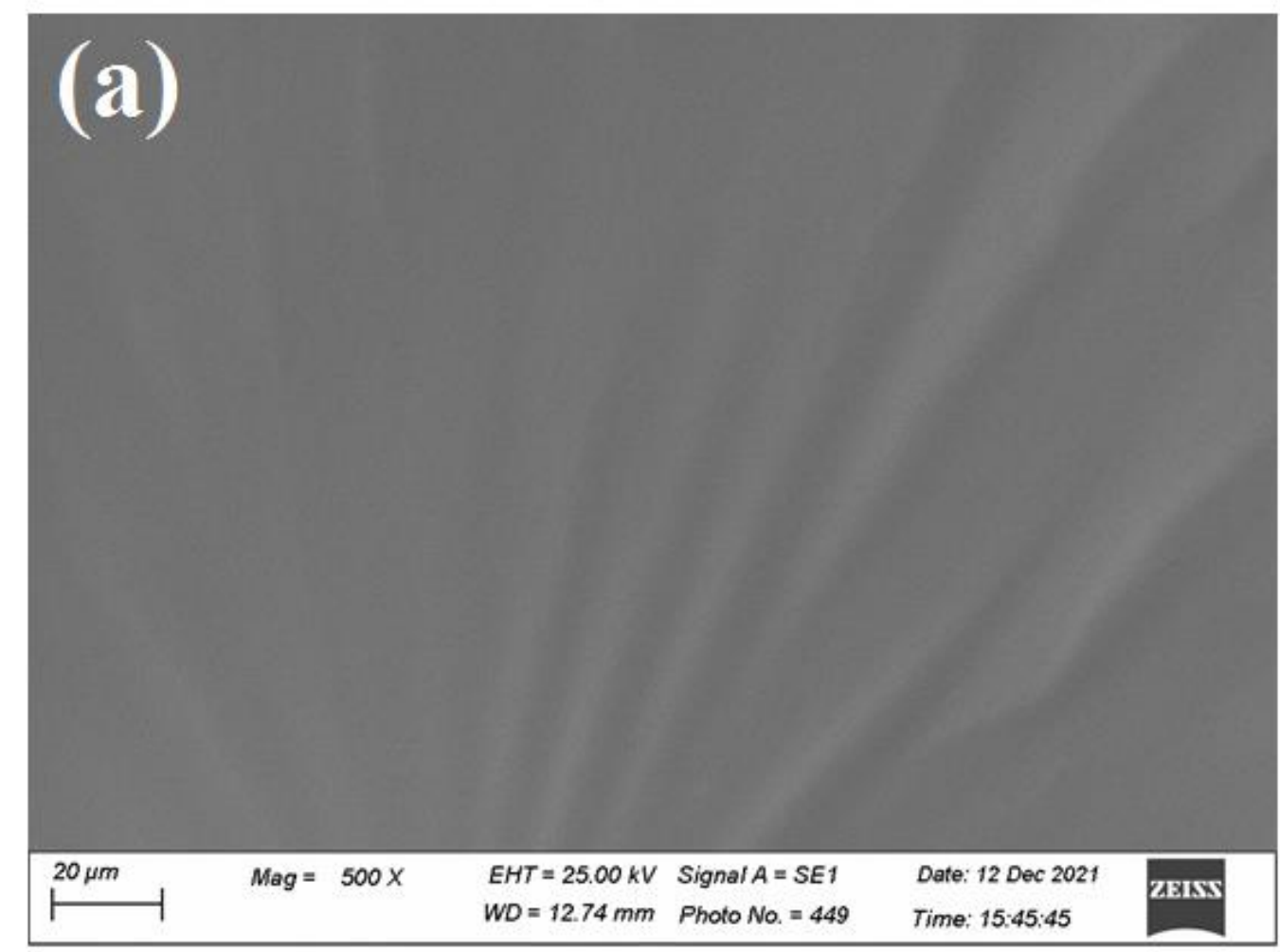



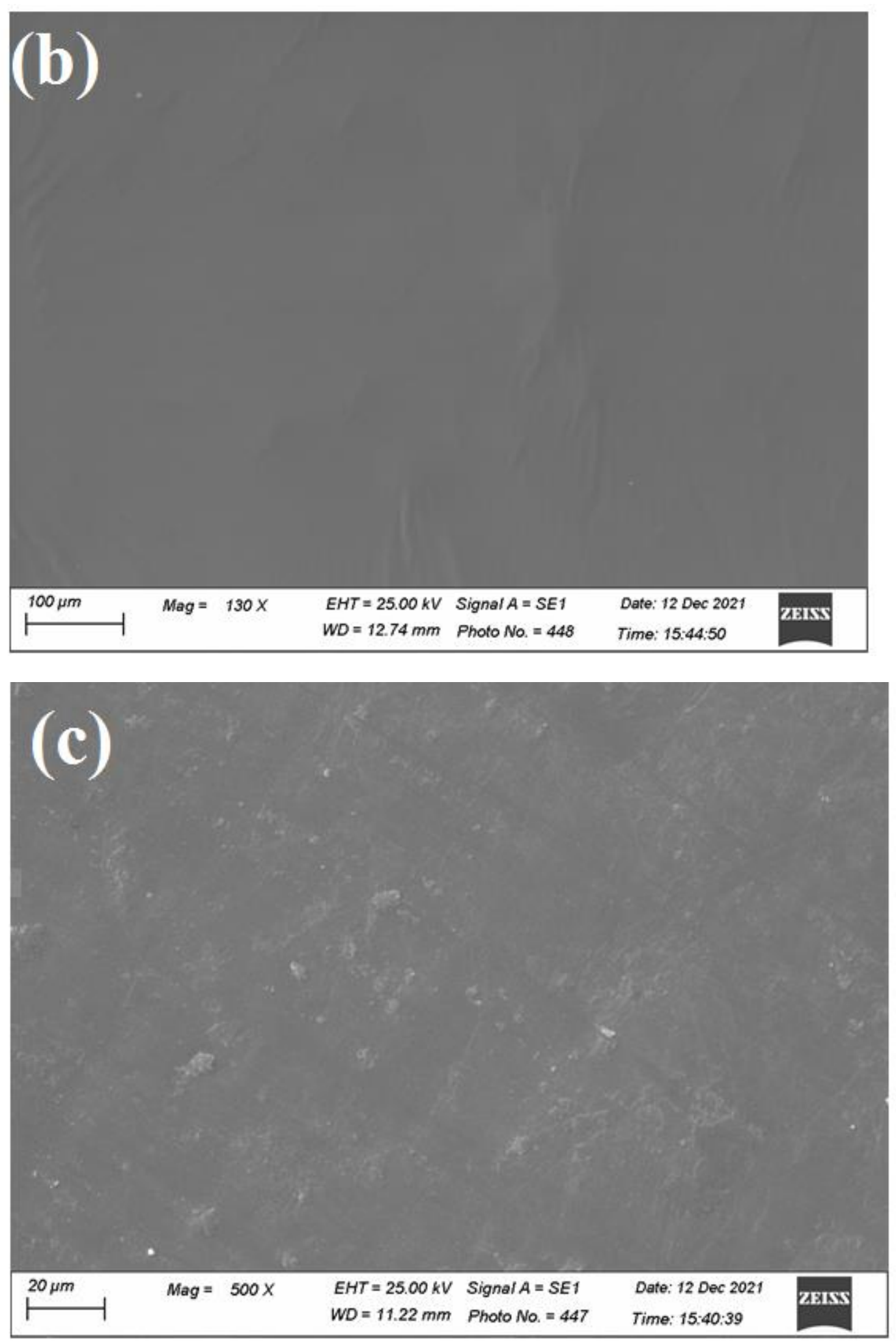

Figure 5. SEM before immersion in SBF for bioglass samples (a) BCD-10 (b) BCD-20 (c) BCD30 

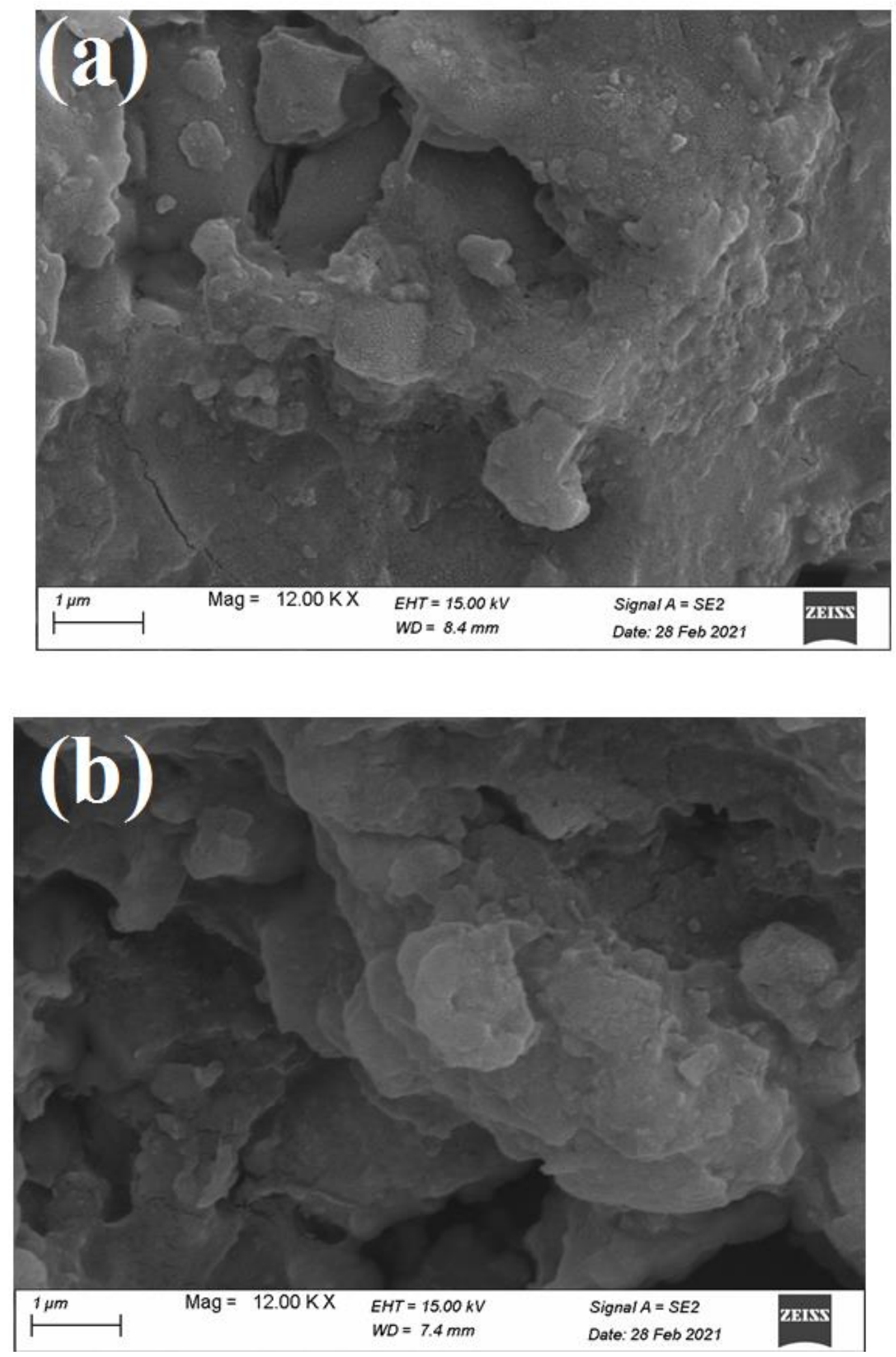


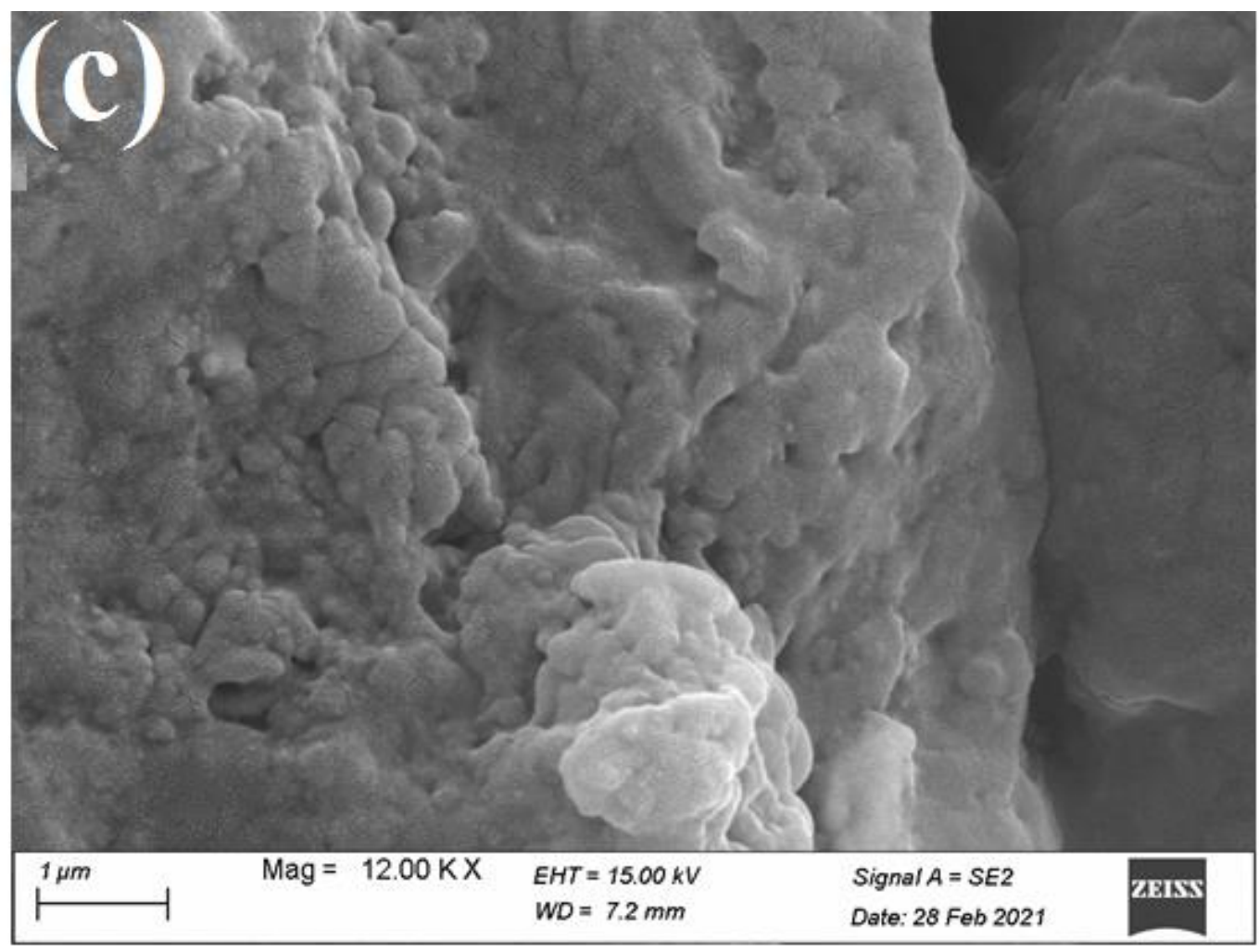

Figure 6. SEM after immersion of 23 days in SBF (a) BDC-10 (b) BCD-20 (c) BCD-30

Ca-P layer has been densed by increasing immersion time in SBF. Also, samples with higher amount of bypass cement dust based glass give higher bioactive surface in view of that Ca-P layer formed in shorter time when immersed in SBF. Hydroxyapatite layer is the main requirement to make artificial bone that is able to bond with natural bone. Hydroxyl-apatite layer is seen to be similar to natural bone composition, so surrounded natural bone can be able to contact directly with this hydroxyl-apatite layer by chemical reaction between surrounding SBF and the artificial bone (bioglassBCD) [30, 34]

\subsection{Shielding parameters}

The Phy-X program is used to determine the gamma/ X-ray radiation parameters as the gamma MAC values of the BCD-30, it's shown in Figure 7 at energy range from 40 to $200 \mathrm{KeV}$. It can be seen in Figure 7, MAC values are in range from 0.639 to $0.126\left(\mathrm{~cm}^{2} / \mathrm{g}\right)$ at 40 to $200 \mathrm{KeV}$ respectively, by the increment in $\mathrm{y}$ energies, MAC values decrease. It is found that the photoelectric absorption is the most dominant mechanism at low energy where the absorption is decreased that is the main cause of reducing in the attenuation coefficient. 


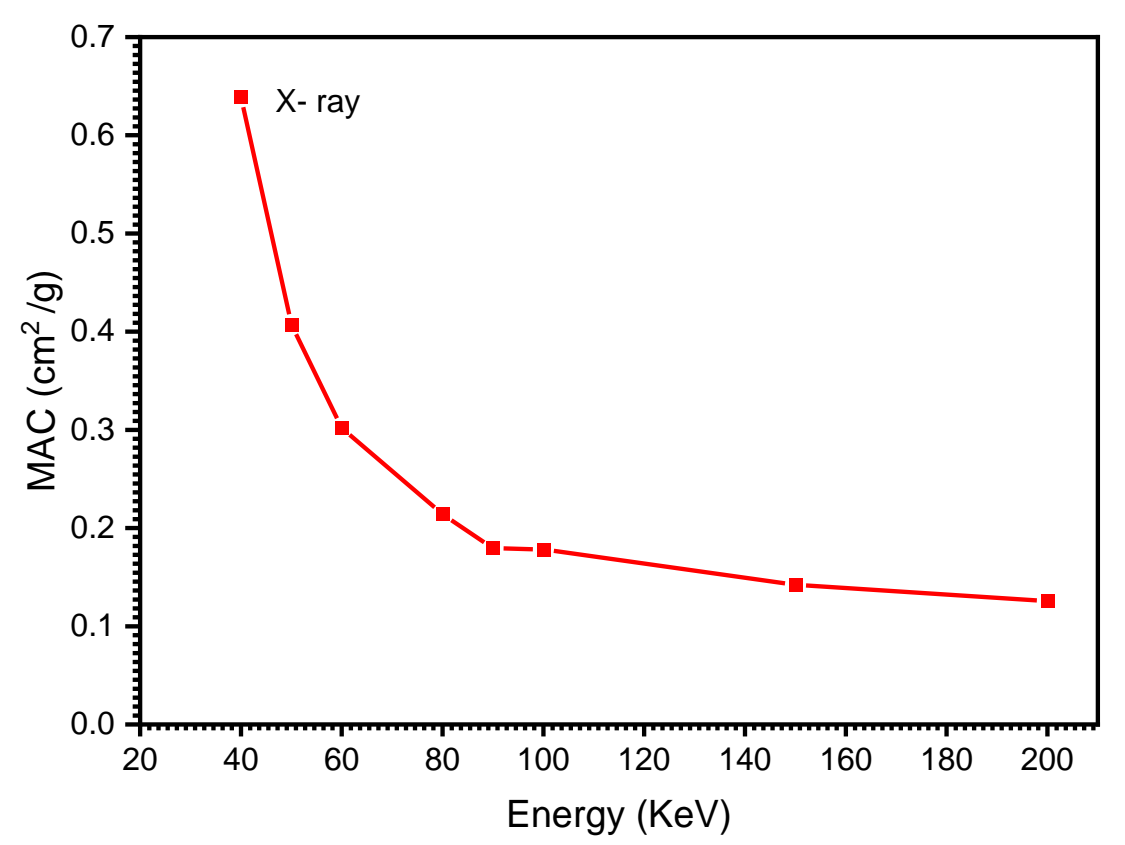

Figure 7. Variation of mass attenuations coefficients (MAC) for BCD-30 glass with photon energy.

Another significant parameter, REP \%, which provides vital information about the material's shielding efficacy, is seen in Figure 8 at same energies of MAC. RPE\% values range from $65 \%$ at $40 \mathrm{KeV}$ to be $19 \%$ at $200 \mathrm{KeV}$. So, its suitable to uses as shielding against $\mathrm{X}$ - rays. To avoid the blind absorption zones and extreme toxicity of shielding materials loaded with lead especially for X-rays in the range from 40 to $200 \mathrm{keV}$.

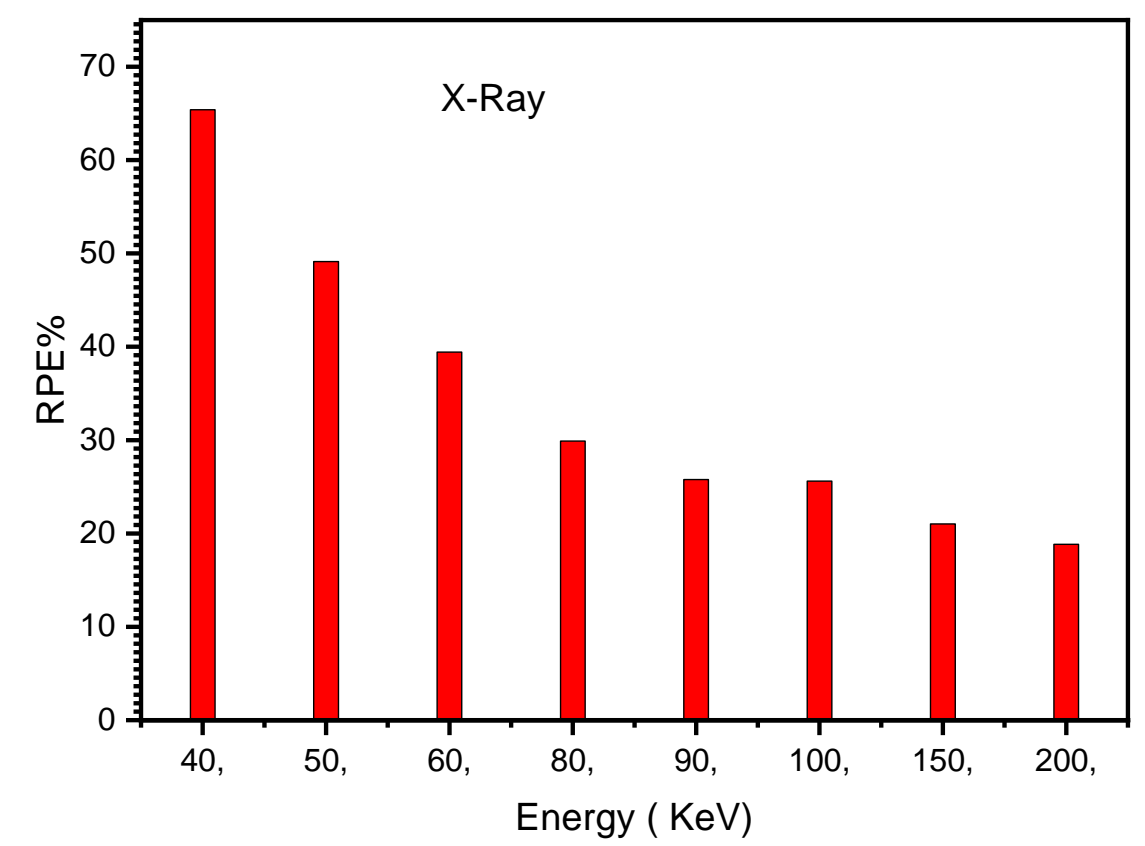

Figure 8. Variation of radiation protection efficiency (RPE\%) for BCD-30 glass with photon energy

According to Figure 9a, MSP for proton values rise sharply with increasing protons Kinetic energy (KE) from $10 \mathrm{KeV}$, reaching maximum values $0.796(\mathrm{MeV}$ 
$\mathrm{cm} 2 / \mathrm{mg})$ at $0.07 \mathrm{MeV}$ for bone tissue and $0.561(\mathrm{MeV} \mathrm{cm} / 2 \mathrm{mg})$ at $0.08 \mathrm{MeV}$ for BCD-30 glass, respectively, with further KE enhancement, MSP values decreased progressively. Furthermore, the MSP values of the BCD-30 glass are lower than those of bone. When seen in these graphs, proton mass stop power levels grow and decrease as kinetic energy is minimized.

The computed protons range values for BCD-30 glass and human bone tissue are shown in Figure 9b within the kinetic energy range of $0.015-10 \mathrm{MeV}$. In general, when compared to bone, the proton can be well stood by BCD-30. The results showed that BCD-30 glass had lower proton MSP and range values than bone. Protons $(\mathrm{H}$ ions) with energy of $10 \mathrm{MeV}$ may achieve a range of around $934 \mathrm{~m}$ and $1290 \mathrm{~m}$ for BCD-30 and bone, respectively; where, projected range worth is expressed that reflects the average values for the slowness in the depth of protons ions.
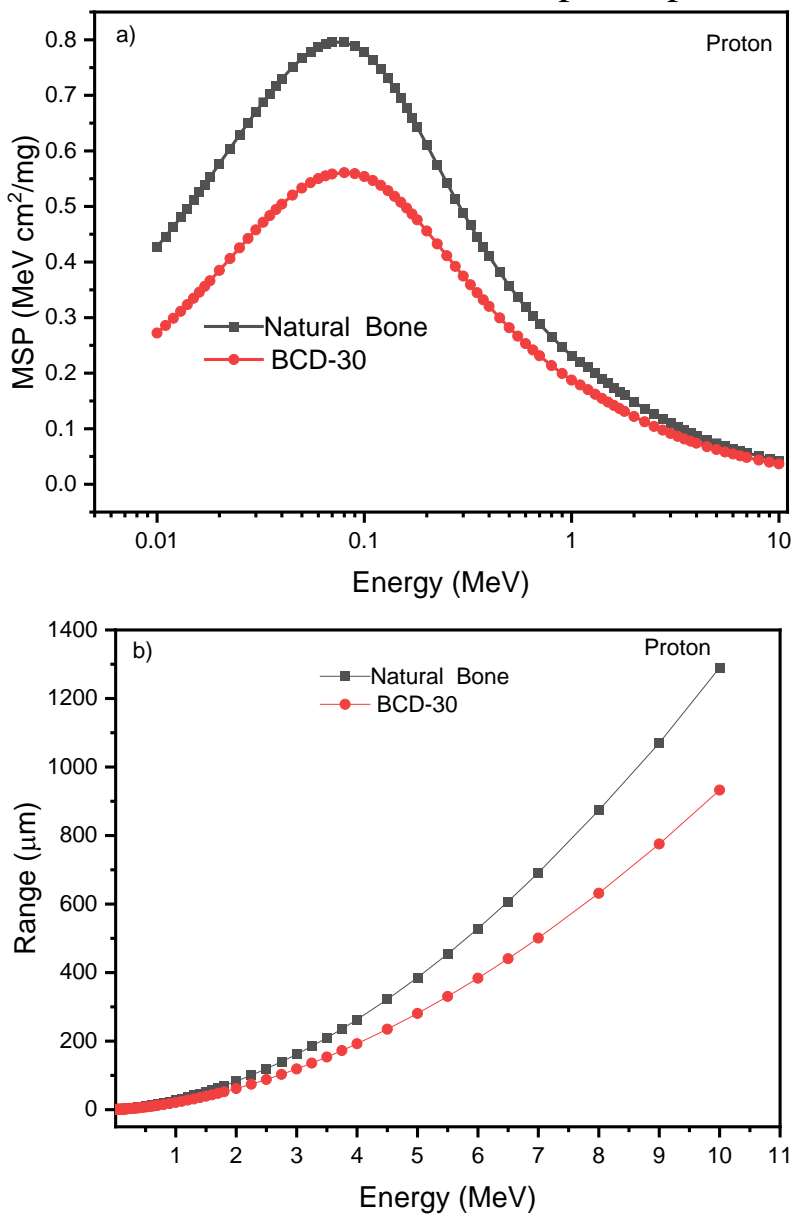

Figure 9. Variation of proton (a) mass stopping powers (MSP) and (b) projected range as a function of kinetic energy for BCD-30 glass and human bone tissue

The alpha MSP and project range for CBD-30 glass and bone are displayed in Figure 10 in the same way as they are for alpha (a-b). According to Figure 10a, starting at 10 $\mathrm{KeV}$ for bone tissue and BCD-30 glass, alpha MSP values rise with rising alpha Kinetic energy (KE), with BCD-30 glass having lower MSP values than bone. The values of alpha MSP for bone and CBD-30 at alpha KE vary from 0.01 to $10 \mathrm{MeV}$ and from 0.417 to $0.508(\mathrm{MeV} \mathrm{cm} / \mathrm{mg})$ with a maximum value of $2.042(\mathrm{MeV}$ $\left.\mathrm{cm}^{2} / \mathrm{mg}\right)$ at $0.6 \mathrm{MeV}$ and from 0.291 to $0.421(\mathrm{MeV} \mathrm{cm} / \mathrm{mg})$ with a maximum value of $1.522\left(\mathrm{MeV} \mathrm{cm}^{2} / \mathrm{mg}\right)$ at $0.65 \mathrm{MeV}$. 
In addition, Figure 10b depicts the alpha range for bone and CBD-30 glass for alpha $\mathrm{KE}$ ranging from 0.01 to $10 \mathrm{MeV}$. According to Figure $10 \mathrm{~b}$, the range of alpha in CBD-30 glass is $0.146 \mu \mathrm{m}$ at $0.01 \mathrm{MeV}$ to $89.43 \mu \mathrm{m}$ at $10 \mathrm{MeV}$, and for bone is 0.107 $\mu \mathrm{m}$ at $0.01 \mathrm{MeV}$ to $65.27 \mu \mathrm{m}$ at $10 \mathrm{MeV}$.
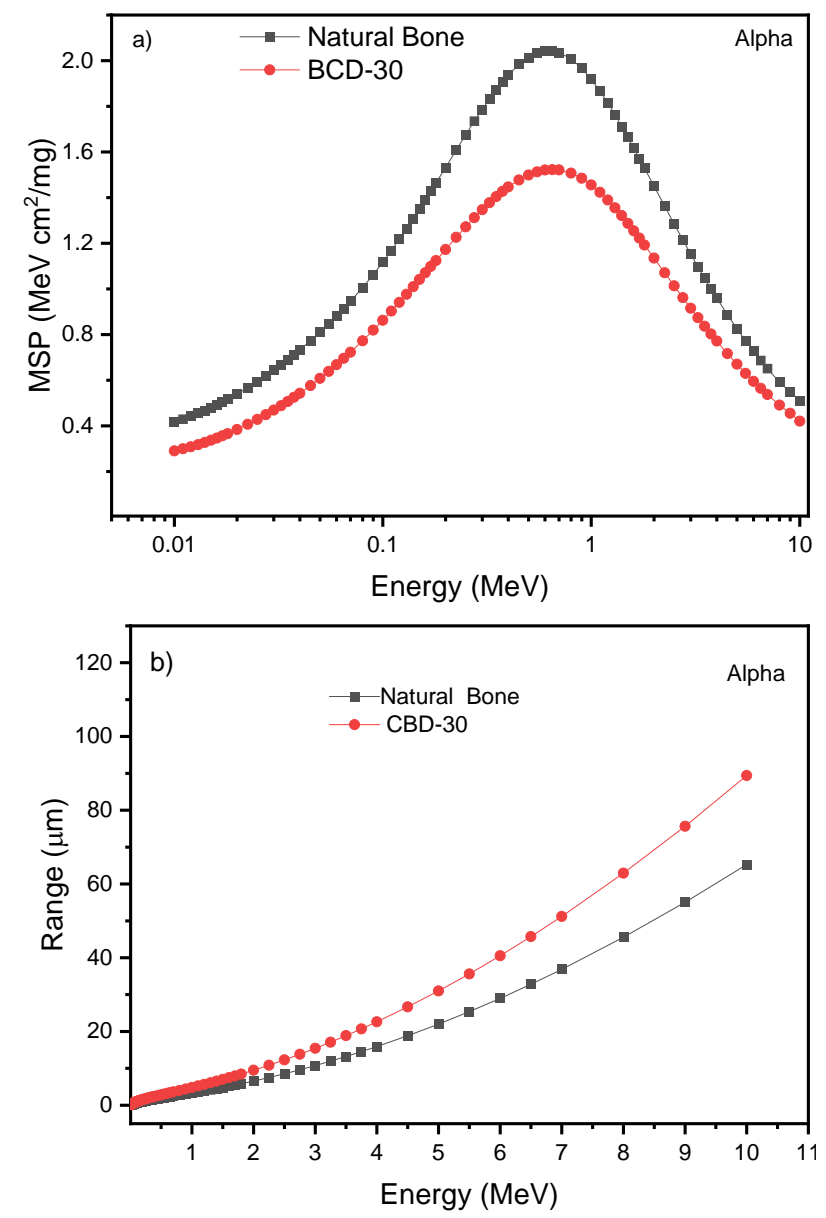

Figure 10. Variation of alpha (a) mass stopping powers and (b) range as a function of kinetic energy for BCD-30 and human bone.

After irradiating a solid with energetic particles, one of radiation damage of materials can be noticed. In the present, the damage caused by the permanent displacement of lattice atoms from their original locations induced by energy transfer in nuclear collisions [35]. The total number of displaced atoms for $100 \mathrm{KeV} \mathrm{H}$ - ions and He-ions in investigated glass and human bone were calculated using the quick TRIM modes; the results are presented in Figure 11 a-d.

Figures 11a and 11b show that the total displacement atoms for CBD-30 glass are 8 atoms per ion, while for bone it is 14 atoms per ion, with no replacement collisions occurring for either target. However from Figure $11 \mathrm{c}, \mathrm{d}$, He-ions at $100 \mathrm{KeV}$ cause total displacement atoms of 109 atoms per ion for bone and 76 atoms per ion for CBD-30 glass, with no replacement collisions occurring for either target. 


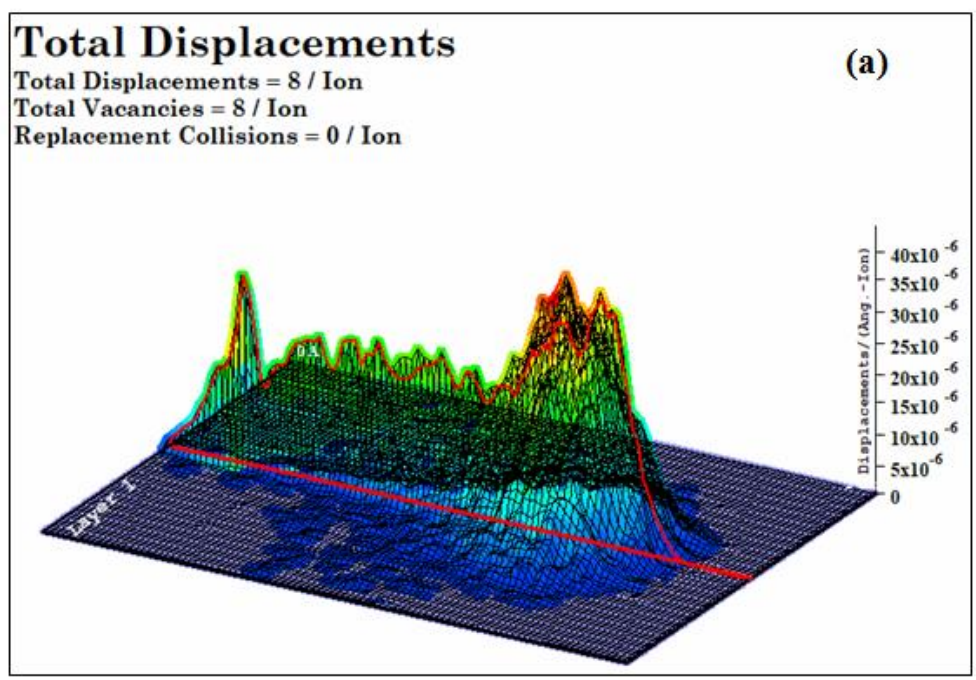

\section{Total Displacements}

Total Displacements $=14 /$ Ion

(b)

Total Vacancies $=14 /$ Ion

Replacement Collisions $=0 /$ Ion

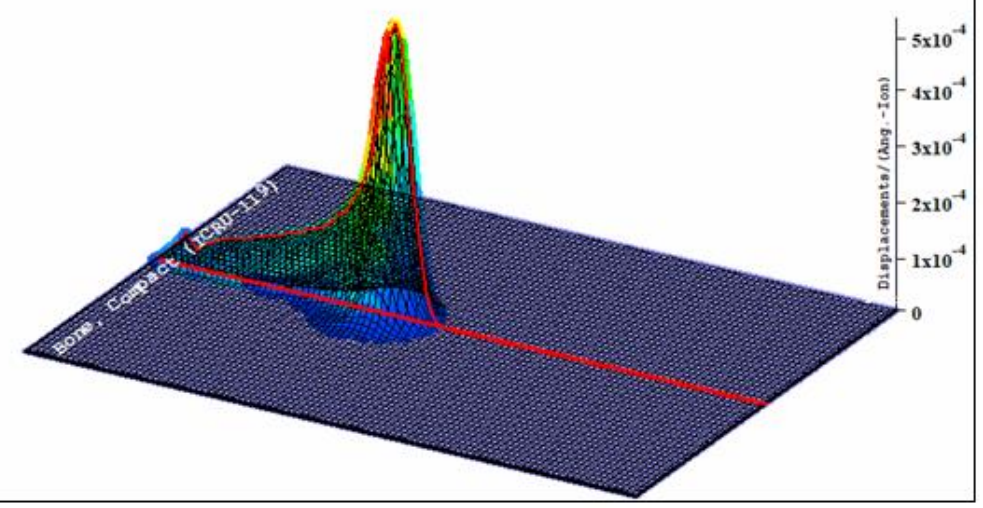



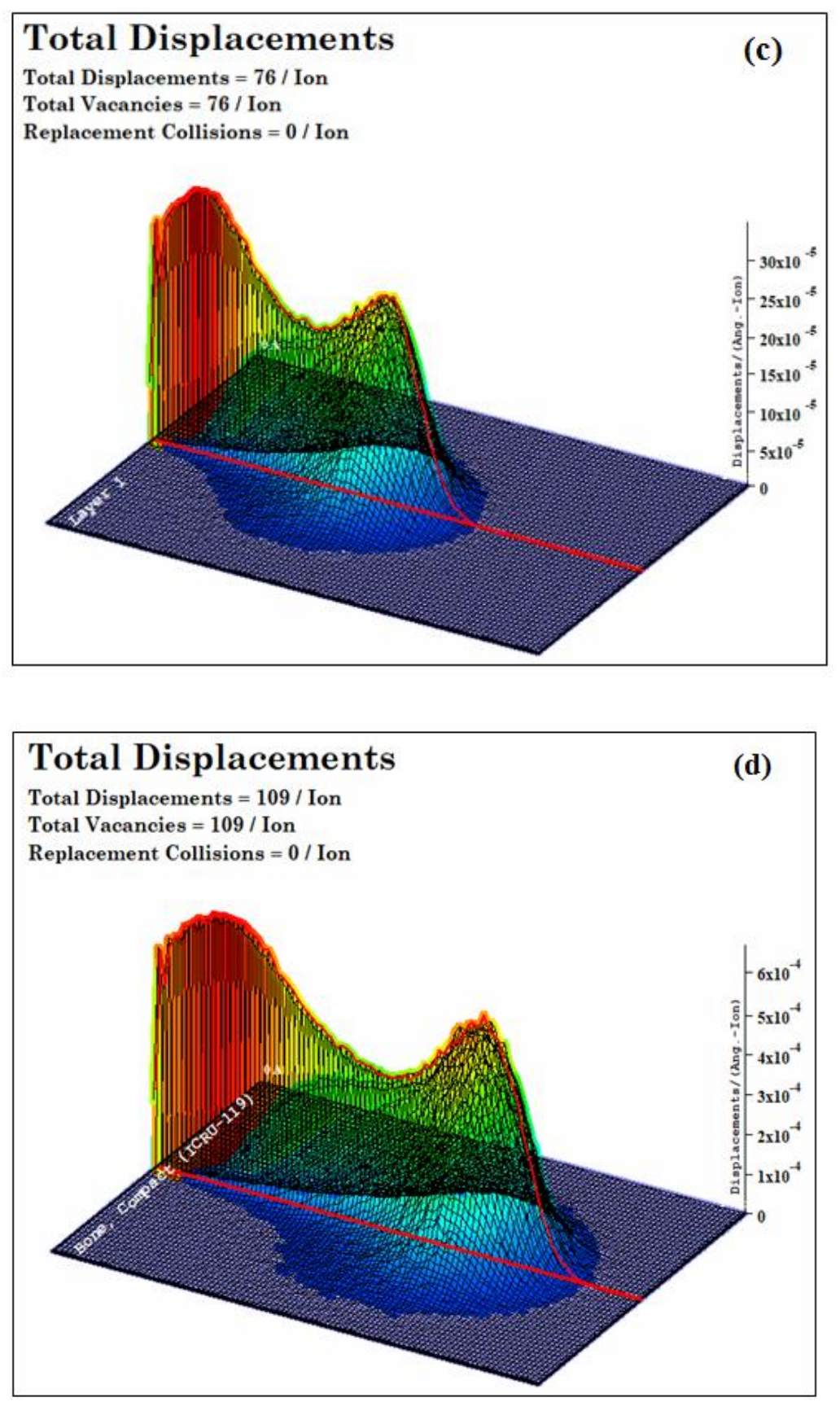

Figure 11. Total number of displaced atoms with $100 \mathrm{KeV}$ of (a) CBD-30 glass exposed to $\mathrm{H}$-ions (b) natural bone exposed to $\mathrm{H}$-ions (c) CBD-30 glass exposed to $\mathrm{He}$-ions (d) natural bone exposed to He-ions with KE $100 \mathrm{KeV}$.

For the ion energies under consideration here, damage is mostly caused by ions transferring energy to target nuclei, resulting in atomic displacements [36]. The damage energy profile can be calculated as the difference between the energy transferred to recoil and energy lost by recoil to ionization at each incremental depth from two output E2RECOIL.TXT and IONIZ.TXT files for fast TRIM run [37].

As illustrated in Figure 12, quick TRIM modes forecast damaging energy for 100 $\mathrm{KeV} \mathrm{H}$-ions and He-ions in examined glass and human bone Figure 12( a-b). 

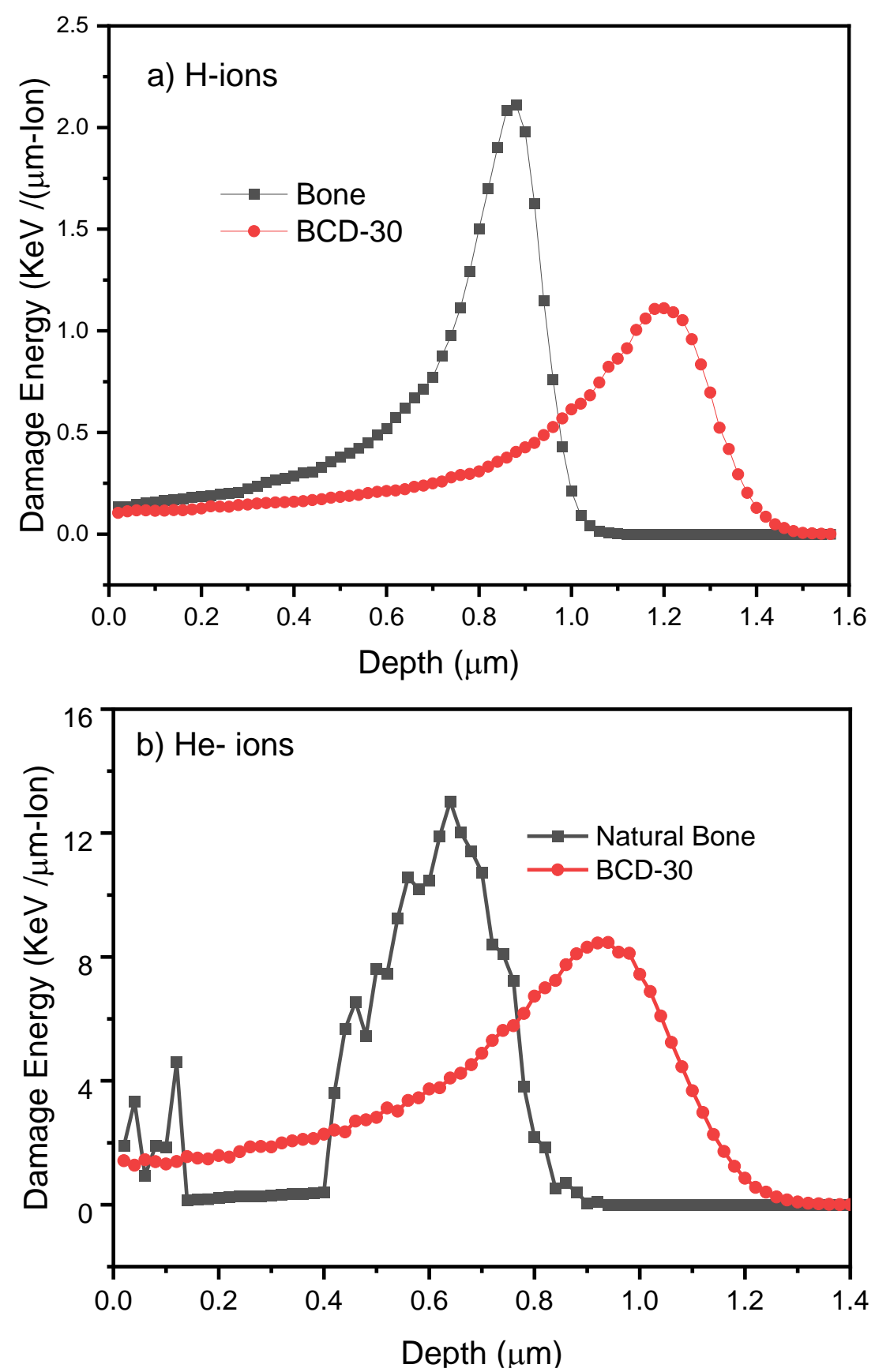

Figure 12. Damge energy at different Depths for BCD-30 glass and natural bone exposed for (a) H-ions and (b) He-ions

It can be shown in Figure $12 \mathrm{a}$ and $\mathrm{b}$ that there is a difference in the damage values for bone and CBD-30 glass at the same depths, indicating a depth shift. The damaging energy profiles in bone are moved to lower depths than in CBD-30 glass, as seen in Figure $12 \mathrm{a}$ and $\mathrm{b}$ the damaging energy curve for $\mathrm{H}$ - ions exhibits a peak at $1.5 \mu \mathrm{m}$ for bone and $1.2 \mu \mathrm{m}$ for CBD-30 glass. A similar deeper damage trend is projected for He-ions, with the damage peak at $0.64 \mu \mathrm{m}$ for bone and $0.93 \mu \mathrm{m}$ for CBD-30 glass at Figure $12 \mathrm{c}$ and $\mathrm{d}$

\section{Conclusions}


Bypass cement dust as one of industrial wastes give a good results in bioactive glass samples. FTIR measurements have been used to determine the main functional groups of the samples; Si and P are found to be the predominant component of the prepared glass samples. When three samples are immersed into the SBF for 13 day calcium phosphate layer is formed from hydroxylcarbonate apatite clearly for glass sample with $30 \% \mathrm{BCD}$ and by smaller ratio in case of 10 and $20 \% \mathrm{BCD}$. The formed HAL become denser by increasing immersion time upto 23 day which is confirmed by FTIR, SEM and Atomic Absorption results. HAL formation has been controlled by the amount of BCD and phosphrous in the composition of the glass. Composition with higher content of BCD and lower phosphrous glass (bioglass-BCD 30) showed good FTIR peaks for HAL, illustrated superior bioactivity response owing to the exchange rate of $\mathrm{Si}, \mathrm{Ca}$ and $\mathrm{P}$ ions. The glass samples fabricated in this work could provide a promising proposal for bone regeneration. Surface change in human bone tissue and CBD-30 glass due to irradiation with hydrogen and helium ions was investigated using the Stopping and Range of Ions in Matter (SRIM)/Transport of Ions in Matter (TRIM) code. The damage profile was analyzed as a function of dpa, and it was discovered that the largest displacement damage peaks are at $1.5 \mu \mathrm{m}$ for bone and $1.2 \mu \mathrm{m}$ for CBD-30 glass owing to $100 \mathrm{KeV}$ of $\mathrm{H}$ ions irradiation; damage peak is at $0.64 \mu \mathrm{m}$ for bone and $0.93 \mu \mathrm{m}$ for CBD-30 glass due to He-ion irradiation. According to these findings, the damage in CBD-30 glass is less severe than in bone, but it is deeper; the average range for $\mathrm{H}$-ions is $1.14 \mu \mathrm{m}$ and $1.56 \mu \mathrm{m}$, respectively.

Funding: This research was funded by the Deanship of Scientific Research, grant number 10197-cos-2020-1-3-I during the academic year 1442 AH/2020 AD.

Institutional Review Board Statement: Not applicable.

Informed Consent Statement: Not applicable.

Data Availability Statement: The data presented in this study are available on request from the corresponding author.

Acknowledgments: The authors gratefully acknowledge Qassim University, represented by the Deanship of Scientific Research, on the financial support for this research under the number "10197-cos-2020-1-3-I during the academic year 1442 AH/2020 AD".

Conflicts of Interest: The authors declare no conflict of interest.

\section{Reference}

1. Lung, C. Y., Abdalla, M. M., Chu, C. H., Yin, I., Got, S. R., \& Matinlinna, J. P. (2021). A Multi-Element-Doped Porous Bioactive Glass Coating for Implant Applications. Materials, 14(4), 961. https://doi.org/10.3390/ma14040961

2. Kargozar, S., Mozafari, M., Hamzehlou, S., Kim, H. W., \& Baino, F. (2019). Mesoporous bioactive glasses (MBGs) in cancer therapy: Full of hope and promise. Materials Letters, 251, 241-246. https://doi.org/10.1016/j.matlet.2019.05.019 
3. Tandon, B., Blaker, J. J., \& Cartmell, S. H. (2018). Piezoelectric materials as stimulatory biomedical materials and scaffolds for bone repair. Acta biomaterialia, 73, 1-20. https://doi.org/10.1016/j.actbio.2018.04.026

4. Kargozar, S., Lotfibakhshaiesh, N., Ai, J., Mozafari, M., Milan, P. B., Hamzehlou, S., ... \& Joghataei, M. T. (2017). Strontium-and cobalt-substituted bioactive glasses seeded with human umbilical cord perivascular cells to promote bone regeneration via enhanced osteogenic and angiogenic activities. Acta biomaterialia, 58, 502-514. https://doi.org/10.1016/i.actbio.2017.06.021

5. Kargozar, S., Hamzehlou, S., \& Baino, F. (2019). Can bioactive glasses be useful to accelerate the healing of epithelial tissues?. Materials Science and Engineering: C, 97, 1009-1020. https://doi.org/10.1016/j.msec.2019.01.028

6. Kargozar, S., Mozafari, M., Hamzehlou, S., \& Baino, F. (2019). Using bioactive glasses in the management of burns. Frontiers in bioengineering and biotechnology, 7, 62. https://doi.org/10.3389/fbioe.2019.00062

7. Mozafari, M., Banijamali, S., Baino, F., Kargozar, S., \& Hill, R. G. (2019). Calcium carbonate: Adored and ignored in bioactivity assessment. Acta biomaterialia, 91, 35-47. https://doi.org/10.1016/j.actbio.2019.04.039

8. Johari, B., Kadivar, M., Lak, S., Gholipourmalekabadi, M., Urbanska, A. M., Mozafari, M., ... \& Kargozar, S. (2016). Osteoblast-seeded bioglass/gelatin nanocomposite: a promising bone substitute in critical-size calvarial defect repair in rat. The International journal of artificial organs, 39(10), 524-533. https://doi.org/10.5301/ijao.5000533

9. Hench, L. L., Splinter, R. J., Allen, W. C., \& Greenlee, T. K. (1971). Bonding mechanisms at the interface of ceramic prosthetic materials. Journal of biomedical materials research, 5(6), 117-141. https://doi.org/10.1002/jbm.820050611

10. Habibovic, P., \& de Groot, K. (2007). Osteoinductive biomaterialsproperties and relevance in bone repair. Journal of tissue engineering and regenerative medicine, 1(1), 25-32. https://doi.org/10.1002/term.5

11. Łączka, M., Cholewa-Kowalska, K., \& Osyczka, A. M. (2016). Bioactivity and osteoinductivity of glasses and glassceramics and their material determinants. Ceramics international, 42(13), 14313-14325. https://doi.org/10.1016/j.ceramint.2016.06.077

12. Initiative, C. S. (2005). CO2 Accounting and Reporting Standard for the Cement Industry. Geneva: World Business Council for Sustainable Development.

13. World Health Organization. (2018). WHO global ambient air quality database (update 2018). World Health Organization: Geneva, Switzerland

14. Adhikary, B. B., \& Mutsuyoshi, H. (2006). Prediction of shear strength of steel fiber RC beams using neural networks. Construction and Building Materials, 20(9), 801-811. https://doi.org/10.1016/j.conbuildmat.2005.01.047

15. Heidbuchel, H., Wittkampf, F. H., Vano, E., Ernst, S., Schilling, R., Picano, E., ... \& ESC Scientific Document Group Jais Pierre 1 de Bono Joseph 2 Piorkowski Christopher 3 Saad Eduardo 4 Femenia Francisco 5. (2014). Practical ways to reduce radiation dose for patients and staff during device implantations and electrophysiological procedures. Europace, 16(7), 946-964. https://doi.org/10.1093/europace/eut409 
16. Newhauser, W. D., \& Zhang, R. (2015). The physics of proton therapy. Physics in Medicine \& Biology, 60(8), R155. https://doi.org/10.1088/0031-9155/60/8/R155

17. Strašík, I., Chetvertkova, V., Mustafin, E., Pavlovič, M., \& Belousov, A. (2012). Depth profiling of residual activity of U 237 fragments as a range verification technique for U 238 primary ion beam. Physical Review Special Topics-Accelerators and Beams, 15(7), 071001. https://doi.org/10.1103/PhysRevSTAB.15.071001

18. Sigmund, P., \& Schinner, A. (2017). Note on measuring electronic stopping of slow ions. Nuclear Instruments and Methods in Physics Research Section B: Beam Interactions with Materials and Atoms, 410, 78-87. https://doi.org/10.1016/i.nimb.2017.08.011

19. Andersen, H. H., \& Sigmund, P. (2002). Stopping of heavy ions: A topical issue. Nuclear Instruments and Methods in Physics Research, Section B: Beam Interactions with Materials and Atoms, 195(1-2), 1-2. https://doi.org/10.1016/S0168-583X(02)01303-4

20. Ziegler, J. F., Ziegler, M. D., \& Biersack, J. P. (2010). SRIM-The stopping and range of ions in matter (2010). Nuclear Instruments and Methods in Physics Research Section B: Beam Interactions with Materials and Atoms, 268(11-12), 1818-1823. https://doi.org/10.1016/j.nimb.2010.02.091

21. Bozkurt, A. (2017). Monte Carlo calculation of proton stopping power and ranges in water for therapeutic energies. In EPJ Web of Conferences (Vol. 154, p. 01007). EDP Sciences. https://doi.org/10.1051/epjconf/201715401007

22. Weber, W. J., \& Zhang, Y. (2019). Predicting damage production in monoatomic and multi-elemental targets using stopping and range of ions in matter code: Challenges and recommendations. Current Opinion in Solid State $\begin{array}{lll}\text { and } \quad \text { Materials } & \text { Science, 23(4), }\end{array}$ https://doi.org/10.1016/j.cossms.2019.06.001

23. Hench, L. L. (1991). Bioceramics: from concept to clinic. Journal of the american ceramic society, 74(7), 1487-1510. https://doi.org/10.1111/j.11512916.1991.tb07132.x

24. Abdeldaym, A., Sallam, O. I., Ezz-Eldin, F. M., \& Elalaily, N. A. (2021). Influence of gamma irradiation on the optical, thermal and electrical features of blue commercial glass as potential accident dosimetry. Journal of Physics and Chemistry of Solids, 110196. https://doi.org/10.1016/j.jpcs.2021.110196

25. Sallam, O. I., Alhodaib, A., Abd El Aal, S., \& Ezz-Eldin, F. M. (2021). Influence of gamma ray on optical and structural properties of commercial glass enriched with copper oxide. Inorganic Chemistry Communications, 124, 108388. https://doi.org/10.1016/j.inoche.2020.108388

26. Elalaily, N. A., Zahran, A. H., Saad, E. A., Sallam, O. I., \& Ezz-Eldin, F. M. (2018). Corrosion and infrared study of some $\gamma$-irradiated lead-phosphate glasses doped with $\mathrm{MoO} \quad 3$. Silicon, 10(4), 16131623.https://doi.org/10.1007/s12633-017-9645-7

27. El-Alaily, N. A., Sallam, O. I., \& Ezz-Eldin, F. M. (2019). Effect of gamma irradiation on some spectroscopic properties of phosphate glass containing samarium ions. Journal of Non-Crystalline Solids, 523, 119604. https://doi.org/10.1016/j.jnoncrysol.2019.119604

28. Sooksaen, P., Pengsuwan, N., Karawatthanaworrakul, S., \& Pianpraditkul, S. (2015). Formation of porous apatite layer during in vitro study of 
hydroxyapatite-AW based glass composites. Advances in Condensed Matter Physics, 2015. https://doi.org/10.1155/2015/158582

29. Dziadek, M., Zagrajczuk, B., Menaszek, E., Wegrzynowicz, A., Pawlik, J., \& Cholewa-Kowalska, K. (2016). Gel-derived SiO2-CaO-P2O5 bioactive glasses and glass-ceramics modified by $\mathrm{SrO}$ addition. Ceramics International, 42(5), $5842-5857$. https://doi.org/10.1016/j.ceramint.2015.12.128

30. Laczka, M., Cholewa - Kowalska, K., Laczka - Osyczka, A., Tworzydlo, M., \& Turyna, B. (2000). Gel - derived materials of a $\mathrm{CaO}$ - P2O5 - SiO2 system modified by boron, sodium, magnesium, aluminum, and fluorine compounds. Journal of biomedical materials research, 52(4), 601-612. https://doi.org/10.1002/1097-4636(20001215)52:4<601::AIDJBM4>3.0.CO;2-I

31. Killion, J. A., Kehoe, S., Geever, L. M., Devine, D. M., Sheehan, E., Boyd, D., \& Higginbotham, C. L. (2013). Hydrogel/bioactive glass composites for bone regeneration applications: Synthesis and characterisation. Materials Science and Engineering: C, 33(7), 4203-4212. https://doi.org/10.1016/j.msec.2013.06.013

32. Kokubo, T., \& Takadama, H. (2006). How useful is SBF in predicting in vivo bone bioactivity?. Biomaterials, 27(15), 2907-2915. https://doi.org/10.1016/j.biomaterials.2006.01.017

33. Miller, C. A., Kokubo, T., Reaney, I. M., Hatton, P. V., \& James, P. F. (2002). Formation of apatite layers on modified canasite glass-ceramics in simulated body fluid. Journal of Biomedical Materials Research: An Official Journal of The Society for Biomaterials, The Japanese Society for Biomaterials, and The Australian Society for Biomaterials and the Korean Society for Biomaterials, 59(3), 473-480. https://doi.org/10.1002/jbm.10018

34. Best, S. M., Porter, A. E., Thian, E. S., \& Huang, J. (2008). Bioceramics: past, present and for the future. Journal of the European Ceramic Society, 28(7), 1319-1327. https://doi.org/10.1016/j.jeurceramsoc.2007.12.001

35. Wesch, W., \& Wendler, E. (2016). Ion beam modification of solids (Vol. 61). Springer Nature. DOI 10.1007/978-3-319-33561-2.

36. Weber, W. J., \& Zhang, Y. (2019). Predicting damage production in monoatomic and multi-elemental targets using stopping and range of ions in matter code: Challenges and recommendations. Current Opinion in Solid State and Materials Science, 23(4),

100757.

https://doi.org/10.1016/j.cossms.2019.06.001

37. Stoller, R. E., Toloczko, M. B., Was, G. S., Certain, A. G., Dwaraknath, S., \& Garner, F. A. (2013). On the use of SRIM for computing radiation damage exposure. Nuclear instruments and methods in physics research section B: beam interactions with materials and atoms, 310.80-75, https://doi.org/10.1016/j.nimb.2013.05.008 